Article

\title{
Functionalized Large-Pore Mesoporous Silica Microparticles for Gefitinib and Doxorubicin Codelivery
}

\author{
Yan $\mathrm{Li}^{1}$, Fangxiang Song ${ }^{2} \mathbb{D}$, Liang Cheng ${ }^{3}$, Jin Qian ${ }^{3}$ and Qianlin Chen ${ }^{1, *}$ \\ 1 Institute of Advanced Technology, Guizhou University, Guiyang 550025, China; yanli@gzu.edu.cn \\ 2 School of Chemistry and Chemical Engineering, Guizhou University, Guiyang 550025, China; \\ sfxgzh1902@163.com \\ 3 School of Electrical Engineering, Guizhou University, Guiyang 550025, China; lcheng1@gzu.edu.cn (L.C.); \\ jqian@gzu.edu.cn (J.Q.) \\ * Correspondence: qlchen@gzu.edu.cn
}

Received: 26 January 2019; Accepted: 2 March 2019; Published: 6 March 2019

\begin{abstract}
Large-pore coralline mesoporous silica microparticles (CMS) were synthesized using the triblock polymer PEG-b-PEO-b-PEG and a hydrothermal method. Scanning electron microscopy (SEM) and transmission electron microscopy (TEM) revealed the coralline morphology of the fabricated materials. The Brunauer-Emmett-Teller (BET) method and the Barrett-Joyner-Halenda $(\mathrm{BJH})$ model confirmed the existence of large pores $(20 \mathrm{~nm})$ and of a tremendous specific surface area $\left(663.865 \mathrm{~m}^{2} \cdot \mathrm{g}^{-1}\right)$ and pore volume $\left(0.365 \mathrm{~cm}^{3} \cdot \mathrm{g}^{-1}\right)$. A novel $\mathrm{pH}$-sensitive multiamine-chain carboxyl-functionalized coralline mesoporous silica material (CMS- $\left.(\mathrm{NH})_{3}-\mathrm{COOH}\right)$ was obtained via a facile "grafting-to" approach. X-ray photoelectron spectroscopy (XPS) and Fourier-transform infrared spectroscopy (FT-IR) validated the effective interfacial functionalization of CMS with carboxyl and multiamine chains. The encapsulation and release behavior of the dual drug (gefitinib (GB) and doxorubicin (DOX)) was also investigated. It was found that CMS- $(\mathrm{NH})_{3}-\mathrm{COOH}$ allows rapid encapsulation with a high loading capacity of $47.36 \%$ for GB and $26.74 \%$ for DOX. Furthermore, the release profiles reveal that CMS- $(\mathrm{NH})_{3}-\mathrm{COOH}$ can preferably control the release of DOX and GB. The accumulative release rates of DOX and GB were $32.03 \%$ and $13.66 \%$, respectively, at a low $\mathrm{pH}$ (pH 5.0), while they reduced to $8.45 \%$ and $4.83 \%$ at $\mathrm{pH} 7.4$. Moreover, all of the modified silica nanoparticles exhibited a high biocompatibility with a low cytotoxicity. In particular, the cytotoxicity of both of these two drugs was remarkably reduced after being encapsulated. CMS-(NH) $)_{3}-\mathrm{COOH} @ G B @ D O X$ showed tremendously synergistic effects of the dual drug in the antiproliferation and apoptosis of A549 human cancer cells in vitro.
\end{abstract}

Keywords: mesoporous silica; multiamine chains; carboxylation; interfacial functionalization; great synergistic effects

\section{Introduction}

Cancer is the leading cause of death in the world. In 2016, there were 17.2 million cancer cases worldwide and 8.9 million deaths [1]. Despite the risk of dying from cancer being reduced in all countries with reliable data, the mortality rates for individuals with lung cancer are increasing, which is a priority for prevention and further research [2]. Chemotherapy is the most common choice in cancer treatment, but it can cause many unwanted side effects. It is important to explore different strategies to enhance cancer therapy. Multidrug combination therapy has become a promising strategy for producing a synergistic response that enhances cancer chemotherapeutic responses [3-8]. The most recent pattern is the combination of traditional chemotherapy drugs and the tyrosine kinase 
inhibitor [9-12]. There are a number of carriers, such as nanoparticles, thermosensitive hydrogels, micelles, and complexed nanoparticles [13-18].

Among various anticancer drugs, water-soluble doxorubicin hydrochloride (doxorubicin hydrochloride) is an effective chemotherapy drug that has been approved for the treatment of various cancers. On the other hand, gefitinib is a specific inhibitor of the epidermal growth factor receptor (EGFR) tyrosine kinase and has been shown to suppress the activation of EGFR signaling required for cell survival and proliferation in non-small-cell lung-cancer (NSCLC) cell lines. It was reported that the codelivery of gefitinib and doxorubicin (DOX) can be used for targeted combination chemotherapy $[9,19,20]$.

Researchers [6] have successfully synthesized a series of mesoporous silica materials in the early 1990s. In 2001, the MCM-41-type mesoporous silica material was first reported as a drug-delivery system. After more than 10 years of development, mesoporous silica materials are now widely used in the field of drug delivery [21-24] (the most commonly used drugs are ibuprofen (IBU) [25,26], aspirin [27], and DOX [28]). They have attracted much attention in the multidrug codelivery field because of their multitude of desirable properties, such as a large specific surface area and entrance, a good biocompatibility, and a low toxicity. AXT/CST-loaded composite nanoparticles (ACML) were prepared in mesoporous silica nanoparticles (MSN) and axtinib (AXT) in a polyethylene glycol liposome bilayer by Choi et al. ACML induces synergistic cancer-cell apoptosis compared to cocktails (AXT/CST). ACML inhibits cell proliferation by blocking mitochondrial function, induces apoptosis, and enhances antitumor effects [7]. The pH-sensitive lipid bilayer $\left(\mathrm{HHG}_{2} \mathrm{C}_{18}\right.$-L) was constructed by using a synthetic zwitterionic oligopeptide lipid (1,5-dioctadecyl-L-glutamy12-histidyl-hexahydrobenzoic acid, $\mathrm{HHG}_{2} \mathrm{C}_{18}$ ) and applied to coat amino-functionalized mesoporous silica nanoparticles MSN-NH $\mathrm{N}_{2}$. Erlotinib and DOX were added to $\mathrm{HHG}_{2} \mathrm{C}_{18}-\mathrm{L}$ and $\mathrm{MSN}-\mathrm{NH}_{2}$, respectively, to obtain $\mathrm{pH}$-sensitive charge-converted Erlotinib/DOX co-loaded nanoparticles (M-HHG $\left.{ }_{2} \mathrm{C}_{18}-\mathrm{L}(\mathrm{E}+\mathrm{D})\right)$. Compared with nonsensitive erlotinib/DOX codelivery nanoparticles (M-SPC-L (E + D)) and the concurrent drug combination, $\mathrm{M}-\mathrm{HHG}_{2} \mathrm{C}_{18}-\mathrm{L}(\mathrm{E}+$ $\mathrm{D})$ has the properties of sequential cross-linked drug release and $\mathrm{pH}$-sensitive charge transfer, and it has a significant synergistic effect on the antiproliferation and apoptosis of A549 human cancer cells in vitro [15].

Based on previous methods [29], we designed a facile synthetic route to produce carboxyl-functionalized large-pore mesoporous silica materials that are able to effectively encapsulate and release gefitinib and doxorubicin. To obtain the desired large pores, we employed triblock poly (ethylene glycol)-b-poly (propylene glycol)-b-(poly(ethylene glycol) (PEG-b-PPG-b-PEG) as the structure-directing template rather than the commonly used block copolymer (Pluronic P123 and F127). Transmission electron microscopy (TEM) images of the obtained materials (large-pore coralline mesoporous silica microparticles; CMS) show that the material possesses an unambiguous open-framework structure. This structure favors efficient mass transfer, as the high-density entrances enable rapid and efficient drug encapsulation. The functionalized part, because of carboxyl, can be combined with the silanol groups but cannot be directly carboxylic-functionalized on a silica mesoporous surface. As it cannot be directly carboxylic-functionalized on a silica mesoporous surface, we designed the amino-functionalized mesoporous silica microparticles by grafting and combined succinic anhydride with the amino to obtain carboxylic-functionalized materials with multiamine chains (CMS- $(\mathrm{NH})_{3}-\mathrm{COOH}$ ) (see Scheme 1).

The CMS and CMS- $(\mathrm{NH})_{3}-\mathrm{COOH}$ were then investigated as drug-delivery vehicles. As shown in the release experiments in a weak-basic ( $\mathrm{pH}$ 7.4) and weak-acid ( $\mathrm{pH}$ 5.0) buffer solutions, they exhibited a high loading capacity and a sustained release of gefitinib and doxorubicin, which verified the significance of the designed experiment and the value of the research (the release rate of DOX and GB in the weak-acid solution was higher than in the weak-basic solution, manifesting the $\mathrm{pH}$ sensitivity of CMS- $\left.(\mathrm{NH})_{3}-\mathrm{COOH}\right)$. 


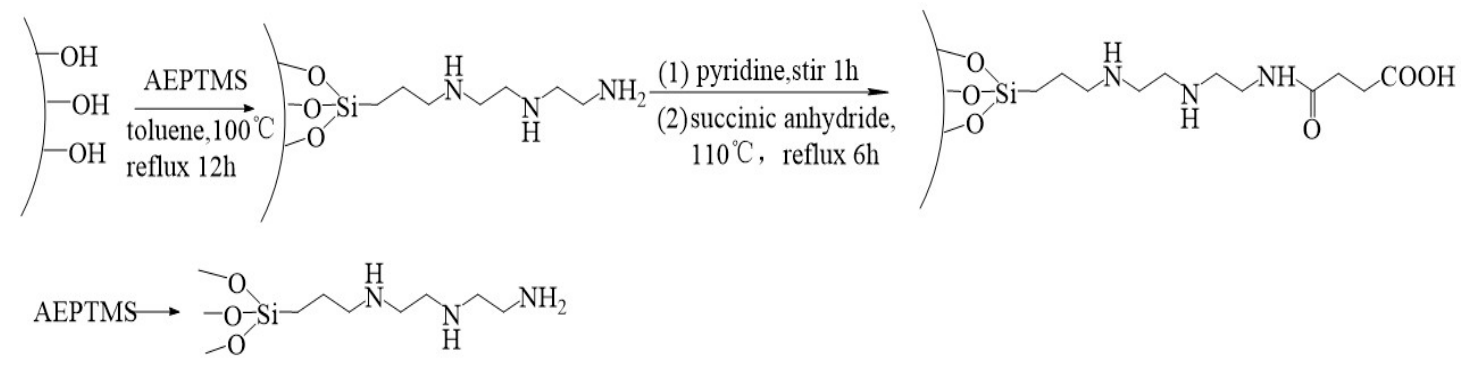

Scheme 1. The formation mechanism of CMS- $(\mathrm{NH})_{3}-\mathrm{COOH}$.

We applied this novel $\mathrm{pH}$-sensitive multiamine-chain carboxyl-functionalized coralline mesoporous silica carrier for A549 human cancer cells in vitro. Gefitinib and DOX were incorporated into CMS- $(\mathrm{NH})_{3}-\mathrm{COOH}$ to obtain $\mathrm{pH}$-sensitive carboxyl-functionalized large-pore mesoporous silica gefitinib/DOX codelivery microparticles (CMS-(NH) $3-\mathrm{COOH} @ \mathrm{DOX} @ \mathrm{~GB})$. Two drugs were conjugated to CMS- $(\mathrm{NH})_{3}-\mathrm{COOH}$ and showed an enhanced uptake in A549 human cancer cells compared with the microparticles obtained with only gefitinib. IC50 doses revealed the potential antiproliferative effect on A549 human cancer cells. Therefore, the dual-drug conjugated CMS- $(\mathrm{NH})_{3}-\mathrm{COOH}$ could be a potential drug carrier for active therapeutic aspects in cancer therapy.

\section{Materials and Methods}

\subsection{Preparation of Carboxyl-Functionalized Large-Pore Mesoporous Silica Microparticles}

Four grams of triblock poly (ethylene glycol)-b-poly (propylene glycol)- $b$-(poly(ethylene glycol) (PEG- $b$-PPG- $b$-PEG), MW = 8400, Aladdin, Shanghai, China) and $20 \mathrm{~mL}$ of hydrochloric acid (36-38\%, Chongqing, China) were added into $120 \mathrm{~mL}$ deionized water. This was stirred for $20 \mathrm{~min}$ until the solution was clarified at room temperature; we then added a $6 \mathrm{~g}$ sodium silicate (Komeo, Tianjin, China) solution (10.5 g sodium silicate dissolved in $10.5 \mathrm{~g}$ deionized water). After stirring for $4 \mathrm{~h}, 15 \mathrm{~mL}$ of anhydrous ethanol was added dropwise to the rest of the $15 \mathrm{~g}$ sodium silicate solution, adding the mixed solution at a rate of $0.3 \mathrm{~mL} / \mathrm{s}$. Next, it was washed at a constant pressure in a split funnel with $5 \mathrm{~mL}$ deionized water; we obtained a pale-blue solution after stirring for $24 \mathrm{~h}$ at $1200 \mathrm{rpm}$. The above mixed solution was poured into the reaction kettle with the polytetrafluoroethylene gallbladder hydrothermal for $24 \mathrm{~h}$ at $120{ }^{\circ} \mathrm{C}$ with a heating rate of $5{ }^{\circ} \mathrm{C} / \mathrm{min}$. The mixture was obtained by a vacuum-suction filter, washed three times with deionized water and anhydrous ethanol, and dried overnight in a drum wind-drying oven at $60^{\circ} \mathrm{C}$. The obtained solid white powder was calcined at $6 \mathrm{~h}$ in a high-temperature tubular-resistant furnace of $550{ }^{\circ} \mathrm{C}$ on air with a temperature of $5^{\circ} \mathrm{C} / \mathrm{min}$; this was named CMS.

We mixed $500 \mathrm{mg}$ of CMS with $40 \mathrm{~mL}$ of dry toluene and performed ultrasonic dispersion for $30 \mathrm{~min}$. Then, $1.5 \mathrm{~mL}$ 3-[2-(2-aminoethylamino) ethylamino]propyl-trimethoxysilane (AEPTMS, $95 \%$, Macklin, Shanghai, China) was added and stirred for $12 \mathrm{~h}$ at $100{ }^{\circ} \mathrm{C}$. The samples obtained by centrifugation, washed three times, and dried for $6 \mathrm{~h}$ at $60^{\circ} \mathrm{C}$ were named CMS- $(\mathrm{NH})_{3}$.

Then, $500 \mathrm{mg}$ of CMS- $(\mathrm{NH})_{3}$ was dispersed in a $50 \mathrm{~mL}$ pyridine solution and stirred for $1 \mathrm{~h}$ at $25{ }^{\circ} \mathrm{C}$. Subsequently, $4.5 \mathrm{~g}$ of succinic anhydride (SAD, 99\%, Aladdin, Shanghai, China) was added and stirred for $6 \mathrm{~h}$ at $110^{\circ} \mathrm{C}$. After cooling to room temperature, the carboxyl-functionalized materials were obtained by filtering, were washed three times with ethanol and deionized water, were dried at $35^{\circ} \mathrm{C}$ for $24 \mathrm{~h}$, and were named CMS- $(\mathrm{NH})_{3}-\mathrm{COOH}$.

\subsection{Characterization Techniques}

\subsubsection{Morphology and Measurements}

Scanning electron microscopy (SEM) images were taken with a JEOL-JSM-7500F (Japan Electronics corporation, Tokyo, Japan) electron microscope operating at $20 \mathrm{KV}$. Transmission electron microscopy 
(TEM) images of samples were observed on a JEM-2100 (Japan Electronics Corporation, Tokyo, Japan) electron microscope at $220 \mathrm{KV}$.

\subsubsection{FT-IR Spectroscopy Measurements}

Fourier-transform infrared (FT-IR) spectra were collected on a Nicolet iS50 (Thermo Fisher Scientific, San Diego, CA, USA) spectrophotometer using $\mathrm{KBr}$ pellets to analyze the bonding architecture and to identify the functional groups present in all samples.

\subsubsection{X-ray Diffraction (XRD) Analysis}

The powder XRD patterns were recorded on a Bruker D8 X-ray diffractometer (Bruker Corporation, Karlsruhe, Germany) with Ni-filtered $\mathrm{CuK} \alpha$ radiation $(40 \mathrm{kV}, 40 \mathrm{~mA})$. The samples were scanned in the $2 \theta$ angular range of $5^{\circ}-80^{\circ}$ with a step size of $0.02^{\circ}$ and a $2 \mathrm{~s}$ acquisition time/step.

\subsubsection{X-ray Photoelectron Spectroscopy (XPS) Analysis}

XPS images of the samples were analyzed with an American Thermo Fisher K-Alpha (San Diego, CA, USA) at $12 \mathrm{KV}$ to analyze the chemical environment of the elements.

\subsubsection{Nitrogen Adsorption-Desorption Analysis}

Nitrogen sorption isotherms were measured with a Micrometrics ASAP 2020. Before measurement, the samples were degassed in a vacuum at $100{ }^{\circ} \mathrm{C}$ for at least $12 \mathrm{~h}$. The Brunauer-Emmett-Teller (BET) method was utilized to calculate the specific surface areas $\left(\mathrm{S}_{\mathrm{BET}}\right)$ using the adsorption data. By using the Barrett-Joyner-Halenda (BJH) model, the pore volumes and pore-size distributions were derived from the adsorption branches of the isotherms.

\subsubsection{Zeta-Potential Analysis}

Before the zeta potential of all samples was measured with a Zetasizer Nano ZS 90 (Malvern, UK), all samples were dispersed at different $\mathrm{pH}$ deionized water solutions ( $\mathrm{pH} 5,6,7.4$, and 8).

\subsection{Drug-Loading Experiment}

DOX (Aladdin, Shanghai, China) was loaded: $30 \mathrm{mg}$ DOX was dissolved in $30 \mathrm{~mL}$ of $5 \%$ phosphate buffer saline (1.5 mL PBS, adding $28.5 \mathrm{~mL}$, deionized), and $60 \mathrm{mg}$ CMS-(NH) $)_{3}-\mathrm{COOH}$ was added. This was stirred at room temperature at $400 \mathrm{rpm}$ for $24 \mathrm{~h}$ while in a dark condition. The loaded samples (named CMS-(NH) $)_{3}-\mathrm{COOH} @ \mathrm{DOX}$ ) were collected after centrifugation at $8000 \mathrm{rpm}$ for $10 \mathrm{~min}$, were washed of the sediment to clarification with $5 \%$ PBS, and were dried in an air-dry oven at $50{ }^{\circ} \mathrm{C}$ for $24 \mathrm{~h}$. To calculate the DOX loading rate [30], we used an ultraviolet spectrophotometer UV-6100s (Mapuda, Shanghai, China) at $480 \mathrm{~nm}$ and took the average after repeating three times to measure absorbance.

GB (Aladdin, Shanghai, China) was loaded: $30 \mathrm{mg}$ GB was dissolved in $30 \mathrm{~mL}$ of dichloromethane $(\mathrm{DCM})$, and $60 \mathrm{mg}$ of $\mathrm{CMS}-(\mathrm{NH})_{3}-\mathrm{COOH}$ was added. This was stirred at room temperature at 400 $\mathrm{rpm}$ for $24 \mathrm{~h}$ in a dark condition. The loaded samples (named CMS-(NH) $3-\mathrm{COOH} @ \mathrm{~GB}$ ) were collected after being centrifuged at $8000 \mathrm{rpm}$ for $10 \mathrm{~min}$, were washed of the sediment to clarification with DCM, and were dried in an air-dry oven at $50{ }^{\circ} \mathrm{C}$ for $24 \mathrm{~h}$. The following steps were the same as above except the absorbance was measured at $252 \mathrm{~nm}$.

GB and DOX was co-loaded: $30 \mathrm{mg}$ of GB was dissolved in $30 \mathrm{ml}$ of dichloromethane (DCM), and $31 \mathrm{mg}$ of CMS- $(\mathrm{NH})_{3}-\mathrm{COOH} @$ DOX was added. The following steps were the same as above, and the loaded samples was named CMS-(NH) $3_{3}-\mathrm{COOH} @$ DOX@GB. To calculate the DOX and GB loading rate respectively, we used an ultraviolet spectrophotometer UV-6100s at $480 \mathrm{~nm}$ and $252 \mathrm{~nm}$ and took the average after repeating three times to measure the absorbance respectively. 


\subsection{In Vitro Cytotoxicity Experiment}

For the in vitro cell culture, human non-small-cell lung-cancer cells (A549) were purchased from the Cell Bank of the Chinese Academy of Sciences (Shanghai, China). Cell culture: Normal A549 cells were cultured using a Dulbecco's Modified Eagle's medium (DMEM) culture medium supplemented with $10 \%(\mathrm{v} / \mathrm{v})$ fetal bovine serum (FBS), antibiotic penicillin $\left(100 \mathrm{U} \cdot \mathrm{mL}^{-1}\right)$, and streptomycin $\left(100 \mu \mathrm{g} \cdot \mathrm{mL}^{-1}\right)$. The cells were cultivated under a humidified atmosphere with $5 \% \mathrm{CO}_{2}$ at $37^{\circ} \mathrm{C}$; 3-(4,5-Dimethylthiazol-2-yl)-2,5-diphenylte-trazolium bromide (MTT) was purchased from Thermo Fisher Scientific.

The in vitro cytotoxicity of CMS, CMS- $(\mathrm{NH})_{3}-\mathrm{COOH}, \mathrm{CMS}-(\mathrm{NH})_{3}-\mathrm{COOH} @ \mathrm{DOX}$, CMS-(NH) $)_{3}-\mathrm{COOH} @ G B$, and CMS-(NH) ${ }_{3}-\mathrm{COOH} @ D O X @ G B$ was evaluated by an MTT assay. Briefly, A549 cells were seeded in 96-well plates $\left(8 \times 10^{3}\right.$ cells/well $)$ and incubated in a $100 \mu \mathrm{L}$ DMEM solution in a $5 \% \mathrm{CO}_{2}$ atmosphere at $37{ }^{\circ} \mathrm{C}$ for $24 \mathrm{~h}$. Then, different concentrations of the CMS, CMS- $(\mathrm{NH})_{3}-\mathrm{COOH}, \mathrm{CMS}-(\mathrm{NH})_{3}-\mathrm{COOH} @ \mathrm{DOX}, \mathrm{CMS}-(\mathrm{NH})_{3}-\mathrm{COOH} @ \mathrm{~GB}$, and CMS- $(\mathrm{NH})_{3}-\mathrm{COOH} @$ DOX@GB solutions were added to the plate and incubated for a further $48 \mathrm{~h}$. Twenty microliters of the MTT solution $(5 \mathrm{mg} / \mathrm{mL})$ was added to each well and incubated for another $4 \mathrm{~h}$. Afterwards, the medium was removed and replaced with $150 \mu \mathrm{L}$ DMSO. After $10 \mathrm{~min}$ of incubation under gentle shaking, the optical-density (OD) values of the alive cells in the plate were provided from a microplate reader model 550 (BiO-Rad, USA) at $490 \mathrm{~nm}$. The final data were determined by the mean value of 8 replicates for each sample.

\subsection{In Vitro Drug Release}

The release experiments of DOX and GB were taken in buffer solutions of $\mathrm{pH} 7.4$ and 5.0, respectively, by heating the same volume of the buffer solution $(50 \mathrm{~mL})$ up to $37^{\circ} \mathrm{C}$ in a water-bath environment. The nanoparticles (10 mg) were placed in 8000-14,000 MWCO (Molecular Weight Cut Off) dialysis bags (Beijing, China) with $4 \mathrm{~mL}$ of the buffer solution and stirred at $400 \mathrm{rpm}$. Immediately, $3 \mathrm{~mL}$ aliquots were taken, and another $3 \mathrm{~mL}$ of the fresh buffer solution was added at the same time. The absorbance of the $3 \mathrm{~mL}$ aliquot was measured at an interval of 480 and $290 \mathrm{~nm}$ wavelengths, respectively, using an ultraviolet spectrophotometer UV-6100s. The accumulative release rate was calculated as follows [31]:

$$
C_{C}=C_{t}+\frac{v}{V} \sum_{0}^{t-1} C_{t}
$$

where $C_{c}$ is the real concentration of DOX and GB released at time $t ; C_{t}$ is the apparent concentration measured by UV-vis spectrometry of the release fluid sample at time $t ; v$ is the sample volume taken at predetermined time intervals; and $V$ is the total volume of the release fluid.

\section{Results and Discussion}

\subsection{Structure and Characteristics of Materials}

\subsubsection{SEM and TEM Analysis}

Figures 1 and 2 are the CMS, CMS- $(\mathrm{NH})_{3}$, and CMS- $(\mathrm{NH})_{3}-\mathrm{COOH}$ of the scanning electron microscopy and transmission electron microscopy images, respectively. The materials are similar to the coral-like microparticles composed of many nanoparticles held together (see Figure 1). Figure 2 shows the TEM images of samples of CMS, CMS- $(\mathrm{NH})_{3}$, and CMS- $(\mathrm{NH})_{3}-\mathrm{COOH}$ at different magnifications, indicating that the CMS before and after surface modification possesses an open-framework structure. The mesopore structure of CMS- $(\mathrm{NH})_{3}$ and CMS- $(\mathrm{NH})_{3}-\mathrm{COOH}$ could not be clearly observed (Figure 2D-I), which indicated the successful coating of the amino and carboxyl groups on the CMS. 

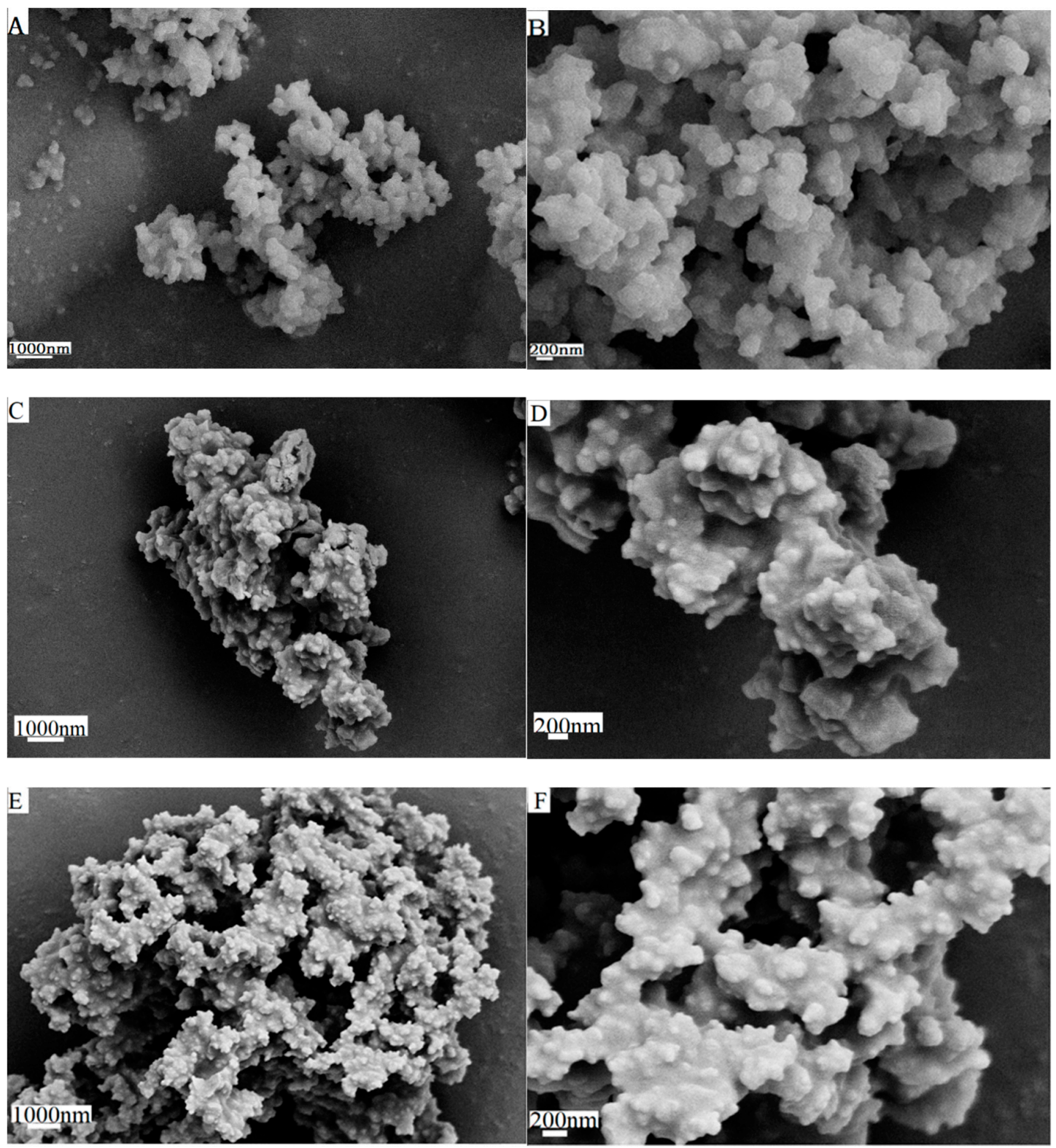

Figure 1. The scanning electron microscopy images of $(\mathbf{A}, \mathbf{B})$ coralline mesoporous silica microparticles (CMS), (C,D) CMS-(NH) $)_{3}$, and (E,F) CMS- $(\mathrm{NH})_{3}-\mathrm{COOH}$.
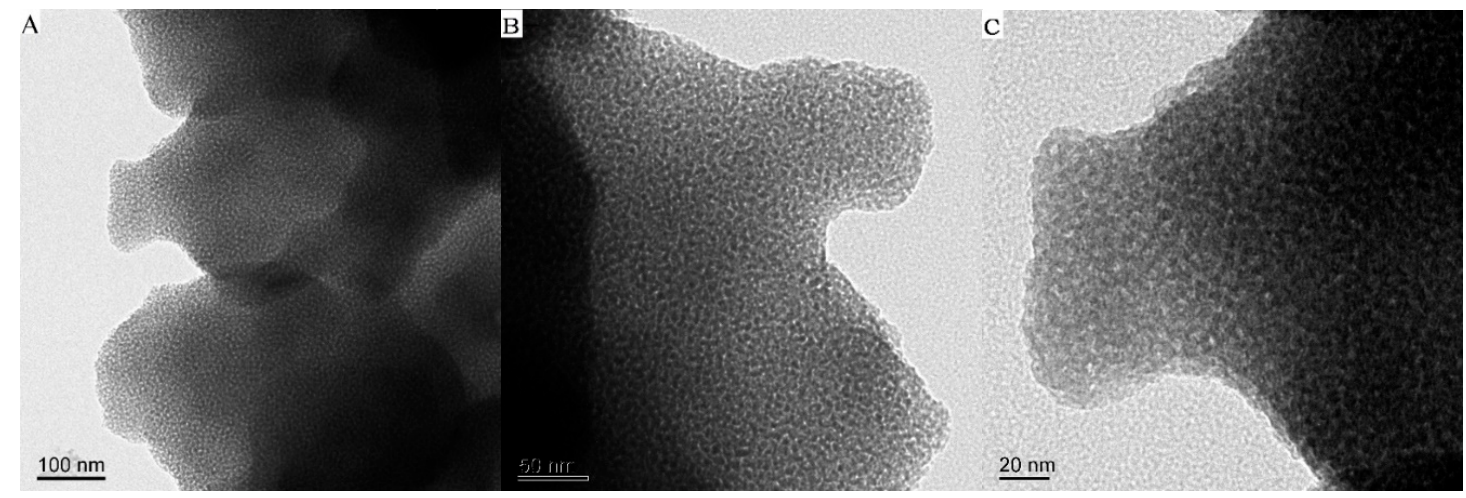

Figure 2. Cont. 

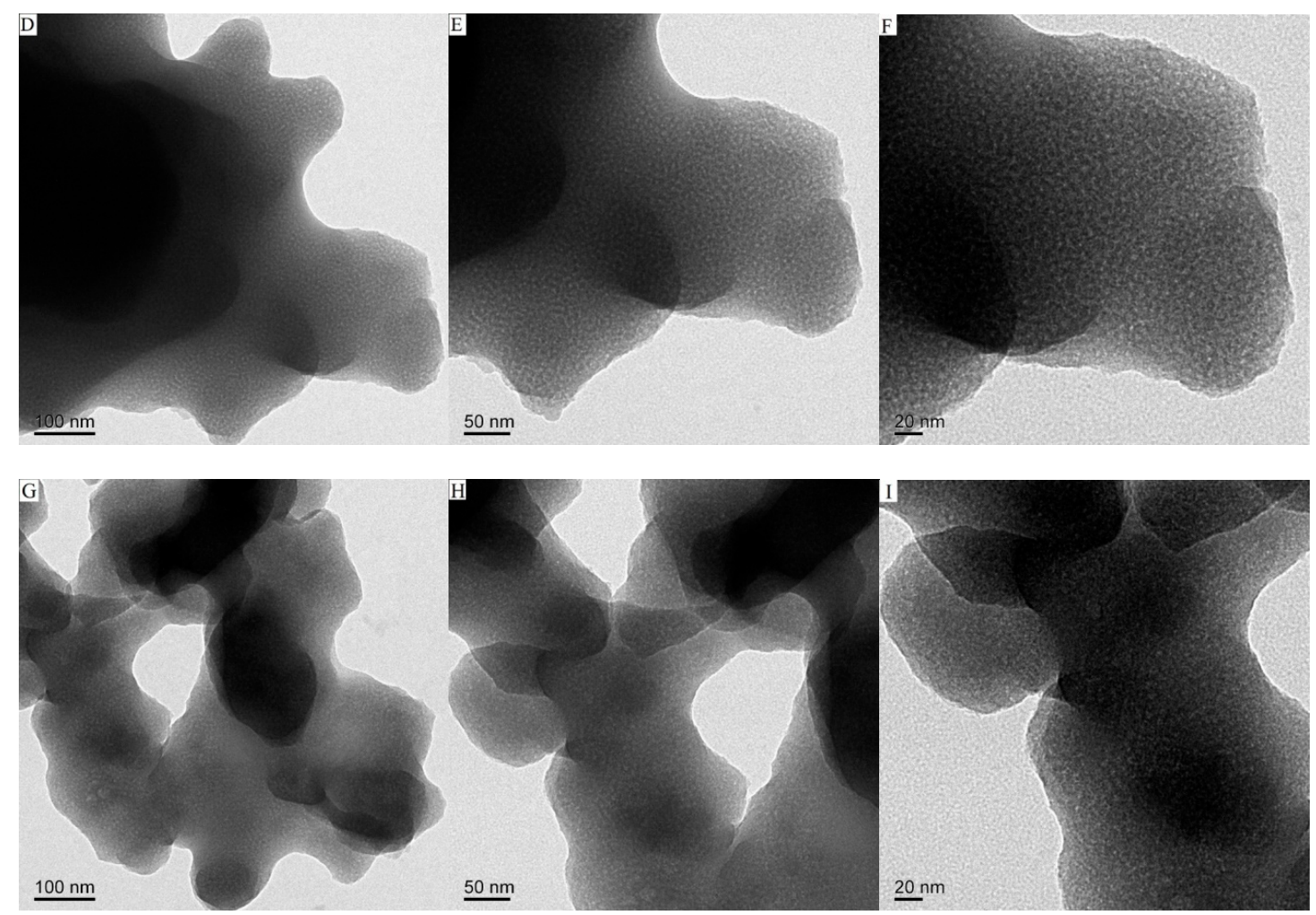

Figure 2. The transmission electron microscopy (TEM) images of (A-C) CMS, (D-F) CMS-(NH) 3 , and $(\mathrm{G}-\mathrm{I}) \mathrm{CMS}-(\mathrm{NH})_{3}-\mathrm{COOH}$

\subsubsection{FTIR Analysis}

Figure 3 shows the FT-IR spectra of all samples. Figure 3A shows that the nonpurified CMS had no obvious characteristic peaks of PEG-PPG-PEG at 2891 and $2942 \mathrm{~cm}^{-1}$ (stretching vibration peaks of $-\mathrm{CH}_{2}$ ) and had the shear vibration peak of $1467 \mathrm{~cm}^{-1}$ of $\mathrm{C}-\mathrm{H}$ [32]. Following template removal, its characteristic peaks disappeared (Figure 3A (b)), which confirmed an effective purification process [33]. However, Figure 3B shows obvious stretching vibration peaks of $-\mathrm{CH}_{2}$. The stretching vibration peaks of Si-O-Si appeared at 1085 and $1212 \mathrm{~cm}^{-1}$, and its asymmetry vibration peaks appeared at $805 \mathrm{~cm}^{-1}$. $\mathrm{Si}-\mathrm{OH}$ had a symmetrical stretching vibration peak at $964 \mathrm{~cm}^{-1}$. The stretching vibration peaks of the $\mathrm{Si}-\mathrm{O}$ bond appeared at $459 \mathrm{~cm}^{-1}$. As for AEPTMS, the bands at 2833 and $2941 \mathrm{~cm}^{-1}$ were stretching vibration peaks of $-\mathrm{CH}_{2}$; the other bands at 3431 and $3278 \mathrm{~cm}^{-1}$ are the $\mathrm{NH}$ stretching vibration peaks of the primary and secondary amines, and the shear vibration peak at $1471 \mathrm{~cm}^{-1}$ is $-\mathrm{CH}_{2}$. However, in Figure 3A (d,e) and Figure 3B (d-f), there is no obvious peak at $964 \mathrm{~cm}^{-1}$. This is because the head group on the AEPTM Sinteracted with the Si-OH with the hydrogen bond. In Figure $3 \mathrm{~A}(\mathrm{~d}, \mathrm{e})$, the peak of $1562 \mathrm{~cm}^{-1}$ was the stretching vibration peak of the $-\mathrm{NH}_{2}$ bending of AEPTMS, indicating that the $\mathrm{NH}_{2}$ groups coupled to the CMS surface. The characteristic absorption peaks of $-\mathrm{COOH}$ were at $1721 \mathrm{~cm}^{-1}$. The peaks at 1561.83 and $1638.36 \mathrm{~cm}^{-1}$ corresponded to amide I (mainly N-H) and amide II (mainly $\mathrm{C}=\mathrm{O}$ stretch) of the $-\mathrm{NH}_{2}$ on the AEPTMS interacting with the succinic anhydride, indicating the formation of CMS- $(\mathrm{NH})_{3}-\mathrm{COOH}$. Gobind et al. [34] and Shen et al. [35] thoroughly analyzed the FT-IR spectra of DOX and GB. After being loaded with DOX and GB, the characteristic absorption peaks of the benzene ring appeared between 1400 and $1600 \mathrm{~cm}^{-1}$, successfully manifesting DOX and GB grafted on the CMS surface. The peak at $2360 \mathrm{~cm}^{-1}$ is the characteristic peak of carbon dioxide that was caused by the system of FT-IR spectra. 

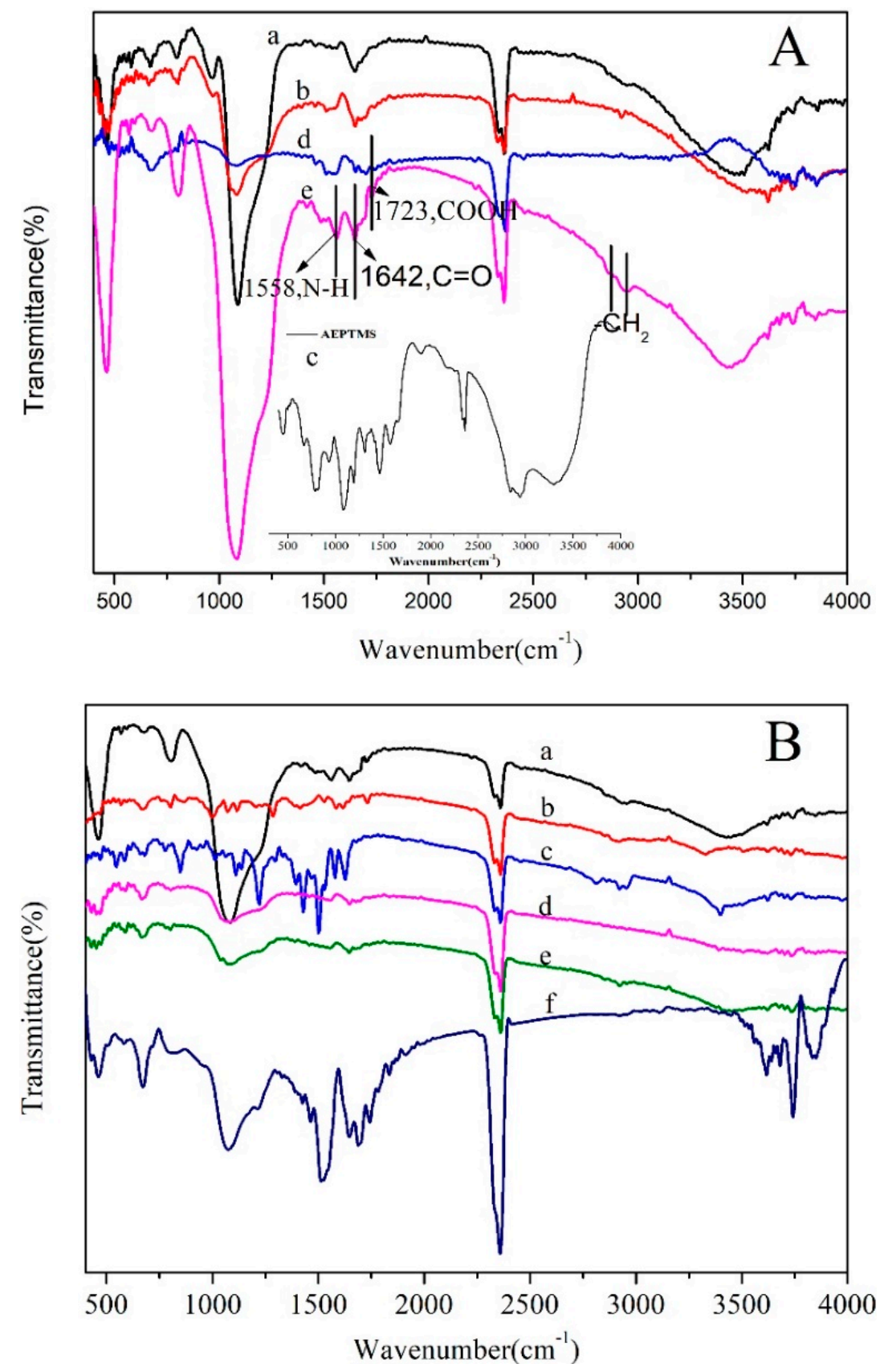

Figure 3. Fourier-transform infrared (FTIR) spectra of (A): (a) CMS/PEG-PPG-PEG, (b) CMS, (c) AEPTMS, (d) CMS- $(\mathrm{NH})_{3}$, and (e) CMS- $(\mathrm{NH})_{3}-\mathrm{COOH}$ and of (B): (a) CMS- $(\mathrm{NH})_{3}-\mathrm{COOH}$, (b) doxorubicin (DOX), (c) gefitinib (GB), (d) CMS-(NH) 3 -COOH@DOX, (e) CMS-(NH) 3 -COOH@GB, and (f) CMS- $(\mathrm{NH})_{3}-\mathrm{COOH} @$ DOX@GB.

\subsubsection{XRD Analysis}

The phases of the samples (CMS, CMS- $(\mathrm{NH})_{3}$ and CMS- $\left.(\mathrm{NH})_{3}-\mathrm{COOH}\right)$ were inspected by XRD (Figure 4). When the template of the mesoporous silica was removed, one distinct broad peak appeared at $2 \theta=15-23^{\circ}$, which corresponded to a typical amorphous silica phase. 


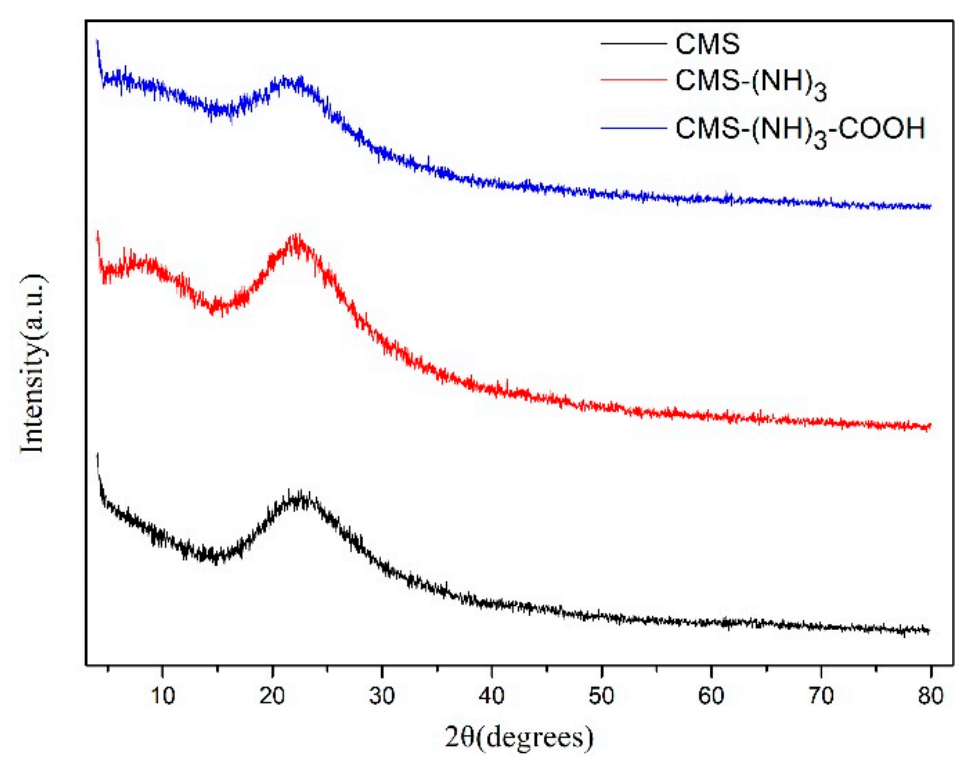

Figure 4. The X-ray diffraction (XRD) pattern of CMS, CMS- $(\mathrm{NH})_{3}$, and CMS- $(\mathrm{NH})_{3}-\mathrm{COOH}$.

\subsubsection{XPS Analysis}

To better evidence the amine and carboxyl successfully grafted on CMS, XPS measurements were carried out on CMS, CMS- $(\mathrm{NH})_{3}$, and CMS- $(\mathrm{NH})_{3}-\mathrm{COOH}$. Through the surveyed spectra in Figure 5 and the data in Table 1, the five peaks of the XPS spectra in Chart A corresponding to silicon signals at $544.18,410.18,300.18,155.08$, and $110.18 \mathrm{eV}$ represent the binding energies for Si2s, Si2p, O1s, N1s, and $\mathrm{C} 1 \mathrm{~s}$, respectively. The $\mathrm{C} 1 \mathrm{~s}$ spectrum was divided into six different peaks attributed to binding energies for $\mathrm{O}-\mathrm{C}=\mathrm{O}(288.48 \mathrm{eV}), \mathrm{C}=\mathrm{O}(287.78 \mathrm{eV}), \mathrm{C}-\mathrm{O}(286.38 \mathrm{eV}), \mathrm{C}-\mathrm{N}(285.58 \mathrm{eV}), \mathrm{C}-\mathrm{C}(284.78 \mathrm{eV})$, and $\mathrm{C}-\mathrm{Si}(\mathrm{C}-\mathrm{Si}-\mathrm{O})(283.74 \mathrm{eV})$, as shown in Figure 5B. The peak of $\mathrm{C}-\mathrm{Si}(\mathrm{C}-\mathrm{Si}-\mathrm{O})$ reveals the presence of the AEPTMS that grafted onto CMS, and the presence of $\mathrm{O}-\mathrm{C}=\mathrm{O}$ and $\mathrm{Si}-\mathrm{C}(\mathrm{O}-\mathrm{Si}-\mathrm{C})$ implies that the amine successfully transformed into carboxyl. The N1s spectrum was divided into six different peaks attributed to the binding energies for $\mathrm{N}-\mathrm{H}(401.05 \mathrm{eV}), \mathrm{O}=\mathrm{C}-\mathrm{N}(399.9 \mathrm{eV})$, and $\mathrm{C}-\mathrm{N}(\mathrm{C}-\mathrm{N}-\mathrm{C})$ $(399.1 \mathrm{eV})$, as displayed in Figure 5C. The peaks of $\mathrm{N}-\mathrm{H}$ and $\mathrm{C}-\mathrm{N}(\mathrm{C}-\mathrm{N}-\mathrm{C})$ suggest the presence of multiamine chains, and only the tail amino carboxylated by succinic anhydride and the presence of $\mathrm{C}=\mathrm{O}$ further confirmed it (see Figure $5 \mathrm{E}$ ). The peak for $\mathrm{O}=\mathrm{C}-\mathrm{N}$ reveals the presence of acylamino.
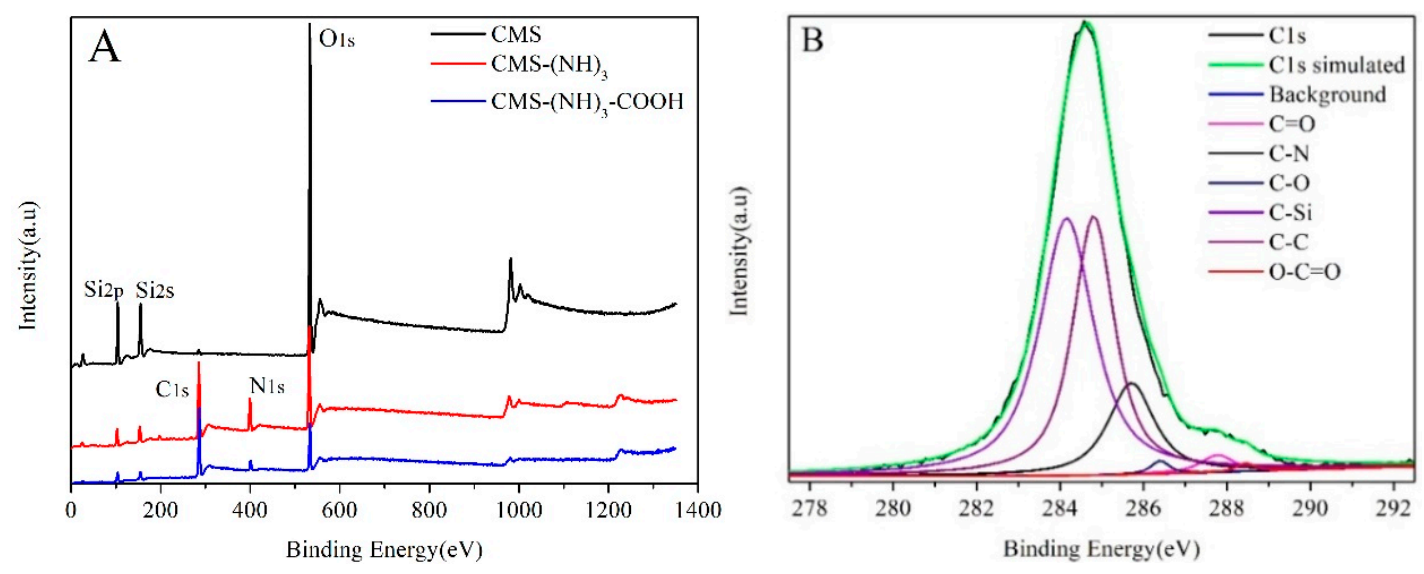

Figure 5. Cont. 

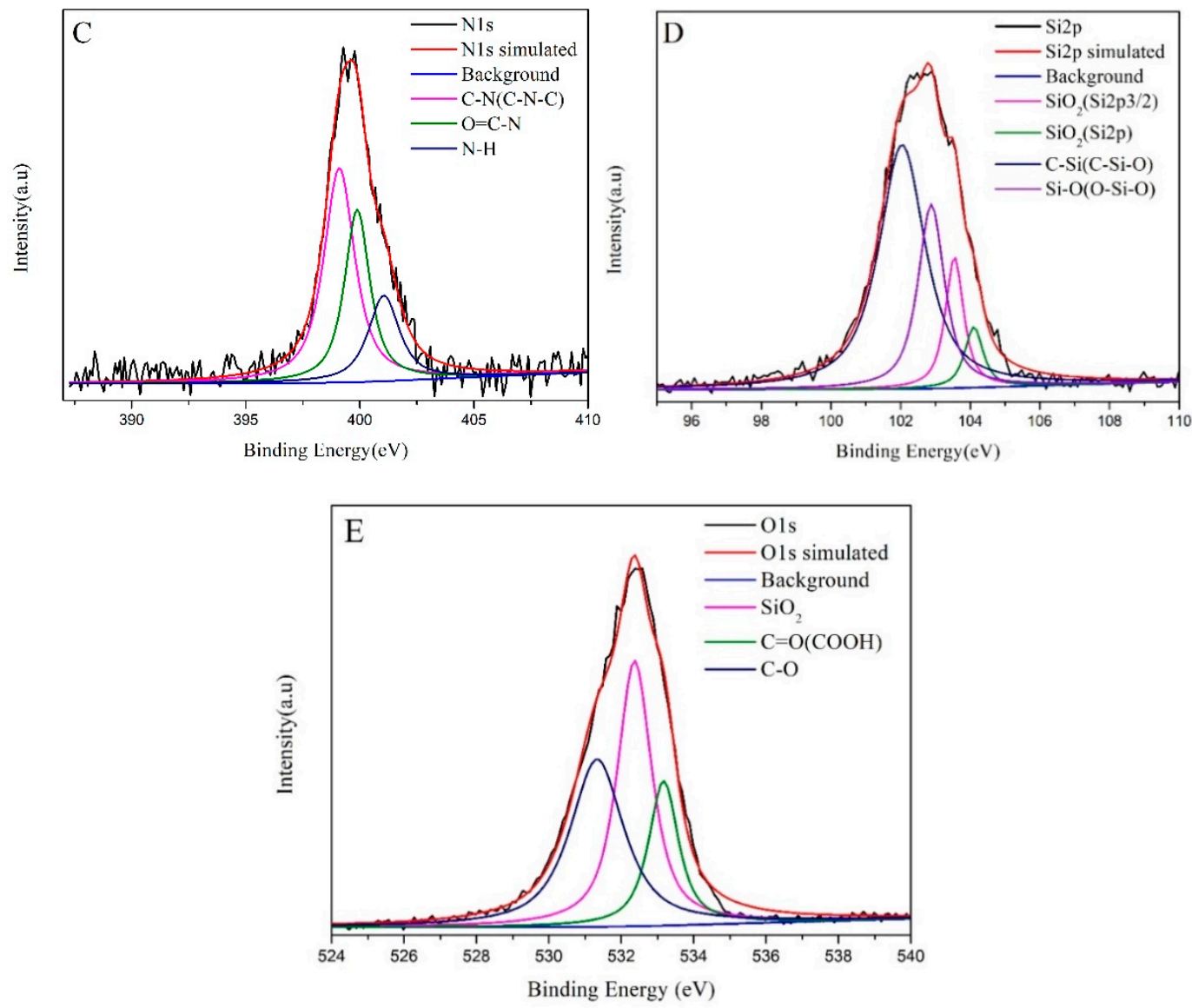

Figure 5. The X-ray photoelectron spectroscopy (XPS) survey spectra for (A) CMS, CMS-(NH) $)_{3}$, and CMS- $(\mathrm{NH})_{3}-\mathrm{COOH},(\mathbf{B}) \mathrm{C} 1 \mathrm{~s}$ of CMS- $(\mathrm{NH})_{3}-\mathrm{COOH},(\mathbf{C}) \mathrm{N} 1 \mathrm{~s}$ of CMS-(NH) $)_{3}-\mathrm{COOH},(\mathbf{D})$ Si2p of CMS- $(\mathrm{NH})_{3}-\mathrm{COOH}$, and (E) O1s of CMS- $(\mathrm{NH})_{3}-\mathrm{COOH}$.

Table 1. The deconvoluted XPS data for C1s, Si2p, N1s, and O1s of CMS- $(\mathrm{NH})_{3}-\mathrm{COOH}$.

\begin{tabular}{|c|c|c|c|}
\hline Elements & Binding Energy (eV) & Atomic (\%) & Bonding Environment \\
\hline \multirow{6}{*}{ C1s } & 283.74 & 19.25 & $\mathrm{C}-\mathrm{Si} / \mathrm{atm} \mathrm{C}$ \\
\hline & 284.78 & 33.95 & $\mathrm{C}-\mathrm{C}$ \\
\hline & 285.58 & 35 & $\mathrm{C}-\mathrm{N} / \mathrm{atm} \mathrm{C}$ \\
\hline & 286.38 & 9.52 & $\mathrm{C}-\mathrm{O} / \mathrm{atm} \mathrm{C}$ \\
\hline & 287.78 & 1.7 & $\mathrm{C}=\mathrm{O}$ \\
\hline & 288.48 & 0.58 & $\mathrm{O}-\mathrm{C}=\mathrm{O}$ \\
\hline \multirow{4}{*}{ Si2p } & 103.55 & 10.95 & $\mathrm{SiO} 2(\mathrm{Si} 2 \mathrm{p} 3 / 2)$ \\
\hline & 104.11 & 5.07 & $\mathrm{SiO} 2(\mathrm{Si} 2 \mathrm{p})$ \\
\hline & 102.04 & 51.81 & $\mathrm{Si}-\mathrm{C}(\mathrm{Si}-\mathrm{O}-\mathrm{C}) / \mathrm{atm} \mathrm{O} / \mathrm{atm} \mathrm{C}$ \\
\hline & 102.88 & 22.17 & $\mathrm{Si}-\mathrm{O}(\mathrm{O}-\mathrm{Si}-\mathrm{O}) / \mathrm{atm} \mathrm{O}$ \\
\hline \multirow{3}{*}{ N1s } & 399.1 & 82.42 & $\mathrm{~N}-\mathrm{C} / \mathrm{atm} \mathrm{C}$ \\
\hline & 399.9 & 53.54 & $\mathrm{O}=\mathrm{C}-\mathrm{N}$ \\
\hline & 401.05 & 32.64 & $\mathrm{~N}-\mathrm{H}$ \\
\hline \multirow{3}{*}{ O1s } & 532.36 & 117.38 & $\mathrm{SiO} 2$ \\
\hline & 533.16 & 55.46 & $\mathrm{O}=\mathrm{C}(\mathrm{COOH}$ and $\mathrm{CONH}) /$ atmo N/atmo $\mathrm{C}$ \\
\hline & 531.33 & 115.24 & $\mathrm{O}-\mathrm{C}$ \\
\hline
\end{tabular}

\subsubsection{Nitrogen-Adsorption-Desorption Analysis}

The $\mathrm{N}_{2}$ adsorption/desorption isotherms, $\mathrm{BJH}$ [36] pore size, and pore-volume distributions of CMS and CMS- $(\mathrm{NH})_{3}-\mathrm{COOH}$ are shown in Figure 6. Figure 6A shows two samples of typical-type IV adsorption isotherms with H2 hysteresis loops in the IUPAC classification [37], indicating the 
presence of large amounts of mesopores. The peak pore diameter was evaluated to be about $20.12 \mathrm{~nm}$ (see Figure 6B). Moreover, the gradually decreased pore size of CMS- $(\mathrm{NH})_{3}-\mathrm{COOH}$ confirmed the functionalized carboxyl. The average pore volume and surface area were estimated via the BET [38] method (see Table 2). Table 2 shows that, after modification, the pore size, specific surface area, and pore volume of CMS were decreased, which indicated part carboxyl chains in mesoporous channels. The decrease of specific surface areas is due to the presence of pendant organic chains covalently bonded to the inorganic network, partially blocking the entrance of nitrogen molecules [39], which indicates that organic groups were fastened in the mesopore.
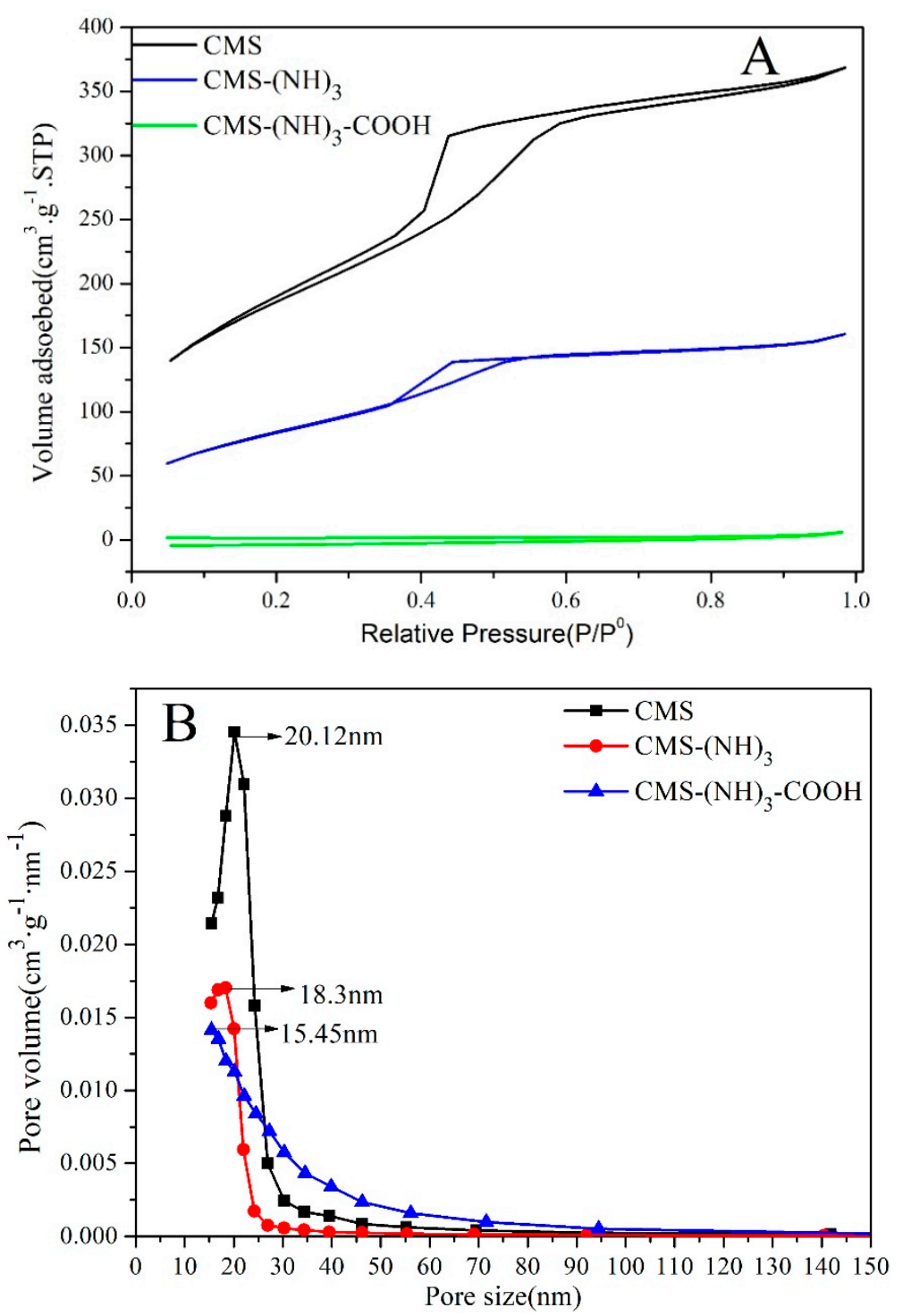

Figure 6. The Brunauer-Emmett-Teller (BET) $\mathrm{N}_{2}$ adsorption-desorption curve (A) and the pore distribution (B) of CMS, CMS- $(\mathrm{NH})_{3}$, and CMS- $(\mathrm{NH})_{3}-\mathrm{COOH}$.

Table 2. The parameters of the samples CMS, CMS- $(\mathrm{NH})_{3}$, and CMS- $(\mathrm{NH})_{3}-\mathrm{COOH}$.

\begin{tabular}{cccc}
\hline Sample & Specific Surface Area & Pore Volume & $\begin{array}{c}\text { Barrett-Joyner-Halenda (BJH) } \\
\text { Adsorption Pore Diameter }\end{array}$ \\
\cline { 2 - 4 } & $\mathbf{S}_{\mathbf{B E T}}\left(\mathbf{m}^{\mathbf{2}} \cdot \mathbf{g}^{-\mathbf{1}}\right)$ & $\mathbf{V}_{\mathbf{p}}\left(\mathbf{c m}^{\mathbf{3}} \cdot \mathbf{g}^{-\mathbf{1}}\right)$ & $\mathbf{D a}(\mathbf{n m})$ \\
\hline $\mathrm{CMS}$ & 663.865 & 0.365 & 20.12 \\
$\mathrm{CMS}-(\mathrm{NH})_{3}$ & 308.043 & 0.299 & 18.345 \\
$\mathrm{CMS}-(\mathrm{NH})_{3}-\mathrm{COOH}$ & 309.157 & 0.147 & 15.448 \\
\hline
\end{tabular}




\subsubsection{Zeta-Potential Analysis}

In addition, the successful surface amine and carboxyl functionalization was confirmed through the zeta-potential measurement of different $\mathrm{pH}$ values $(\mathrm{pH} 5-8)$. As shown in Figure 7, the zeta potential of CMS was $-24.4 \mathrm{mV}$, showing the existence of surface $-\mathrm{OH}$. However, this increased to $5.97 \mathrm{mV}$ (CMS-(NH) 3 ) after being modified with positively charged amine groups. After the modification of succinic anhydride, the zeta potential decreased from 5.97 to $-26.3 \mathrm{mV}$ (CMS- $\left.(\mathrm{NH})_{3}-\mathrm{COOH}\right)$ for the strong negative charge of carboxyl groups rooting in SAD. Generally, nanoparticles are considered to be colloidally stable if the zeta-potential value is below $-25 \mathrm{mV}$ [40]. The functionalized CSM has zeta potential values in the $\mathrm{pH}$ range of $5-8$, as following Figure 7B, indicating that the functionalized CSM is stabile in the $\mathrm{pH}$ range of 5-8. As a result, the introduction of SAD could enhance the stability of the CMS drug-delivery system, which is of critical importance for its therapeutic application [40].
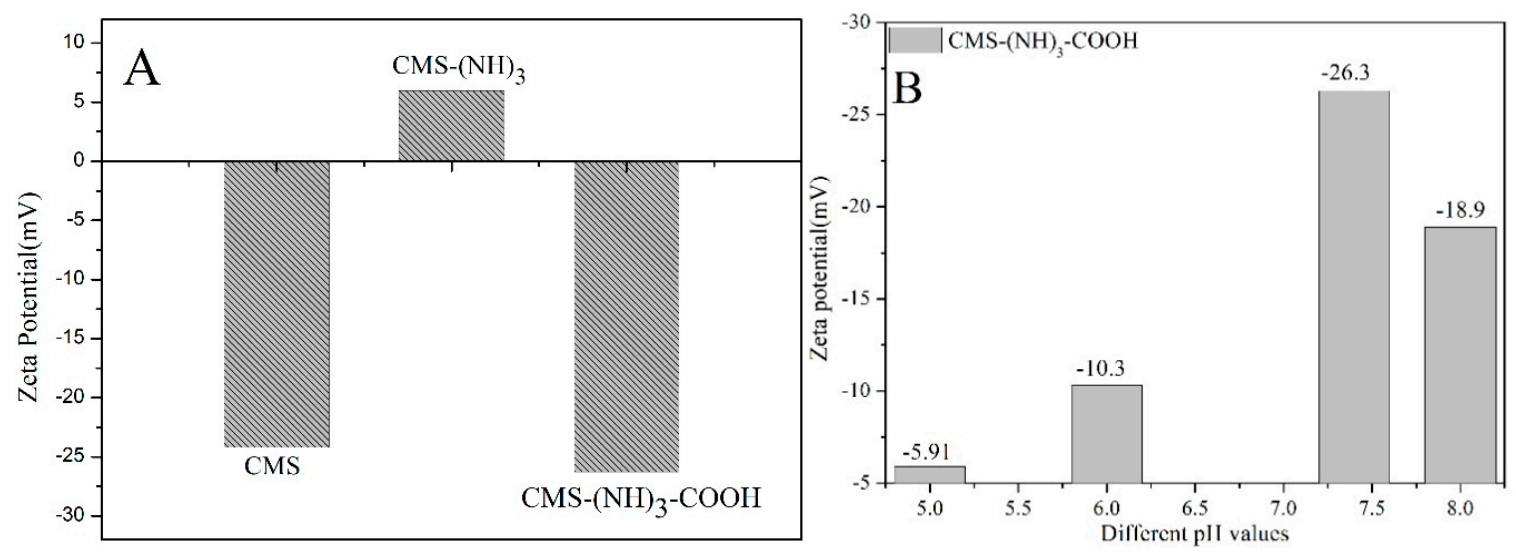

Figure 7. The zeta potential of CMS and functionalized CMS (A) and CMS- $(\mathrm{NH})_{3}-\mathrm{COOH}$ in different $\mathrm{pH}$ values $(\mathbf{B})$.

\subsection{Loading Analysis of DOX and GB}

Five percent phosphate buffer saline was chosen as a solvent to load DOX for the hydrophilia of DOX, while DCM was applied for hydrophobic GB. According to Section 2.5, the calculated contemporary loading of DOX and GB were $25.31 \%$ and $44 \%$, respectively, after the multifunctional groups were grafted. Based on our investigation, we used large-pore mesoporous silica as the carrier to simultaneously load DOX and GB and to achieve a high loading capacity for the first time. The previous works in Table 3 show that CMS- $(\mathrm{NH})_{3}-\mathrm{COOH}$ had the highest loading for DOX and GB. The abundant polyamine chain and carboxyl of CMS- $(\mathrm{NH})_{3}-\mathrm{COOH}$ made it easily react with the amine and hydroxyl of DOX and the amine of GB, and the pore diameter of the material itself $(18.345 \mathrm{~nm})$ is beneficial to loading DOX and GB.

Table 3. Previous work and our work for loading DOX and GB.

\begin{tabular}{|c|c|c|c|c|c|}
\hline \multirow{2}{*}{ Sample } & \multirow{2}{*}{$\begin{array}{l}\text { Including Function } \\
\text { Group }\end{array}$} & \multirow{2}{*}{$\begin{array}{l}\text { Pore Diameter } \\
\text { (nm) }\end{array}$} & \multicolumn{2}{|c|}{ Loading (\%) } & \multirow{2}{*}{ References } \\
\hline & & & DOX & GB & \\
\hline PADMP & $\begin{array}{l}\text { amine, hydrosulphonyl } \\
\text { and carbonyl }\end{array}$ & - & 1.5 & 12 (the highest) & [19] \\
\hline $\begin{array}{l}\text { Nanoparticle made } \\
\text { of PLA-b-PEG }\end{array}$ & hydroxyl and carbonyl & - & 1.42 & 3.16 & [20] \\
\hline CMS- $(\mathrm{NH})_{3}-\mathrm{COOH}$ & $\begin{array}{l}\text { Multiamine chain } \\
\text { and carboxyl }\end{array}$ & 15.45 & 25.31 & 44 & This work \\
\hline
\end{tabular}




\section{In Vitro Cytotoxicity}

The cytotoxicity of blank and DOX- and GB-loaded microparticles toward A549 cells was assessed using a 3-(4,5-dimethyl-2-thiazolyl)-2,5-diphenyl-2-H-tetrazolium bromide (MTT) assay. As can be seen in Figure 8A, after $48 \mathrm{~h}$ incubation, CMS and drugfree CMS- $(\mathrm{NH})_{3}-\mathrm{COOH}$ showed no significant cytotoxicity on A549 cells at different concentration $\left(125,250,500\right.$, and $\left.1000 \mu \mathrm{g} \cdot \mathrm{mL}^{-1}\right)$, indicating both CMS and CMS- $(\mathrm{NH})_{3}-\mathrm{COOH}$ microparticles were very biocompatible and could be accepted in vivo. Nanoparticles are biocompatible at a concentration of up to $2000 \mu \mathrm{g} \cdot \mathrm{mL}^{-1}$ [41]. The inhibition rate also increased with increasing concentration, as expected, manifesting a dose-dependent cytotoxic effect (see Figure 8B-D). The inhibition rates of CMS- $(\mathrm{NH})_{3}-\mathrm{COOH} @$ GB and CMS-(NH) $)_{3}-\mathrm{COOH} @ D O X$ were lower than those of GB and DOX (see Figure 8B,C).
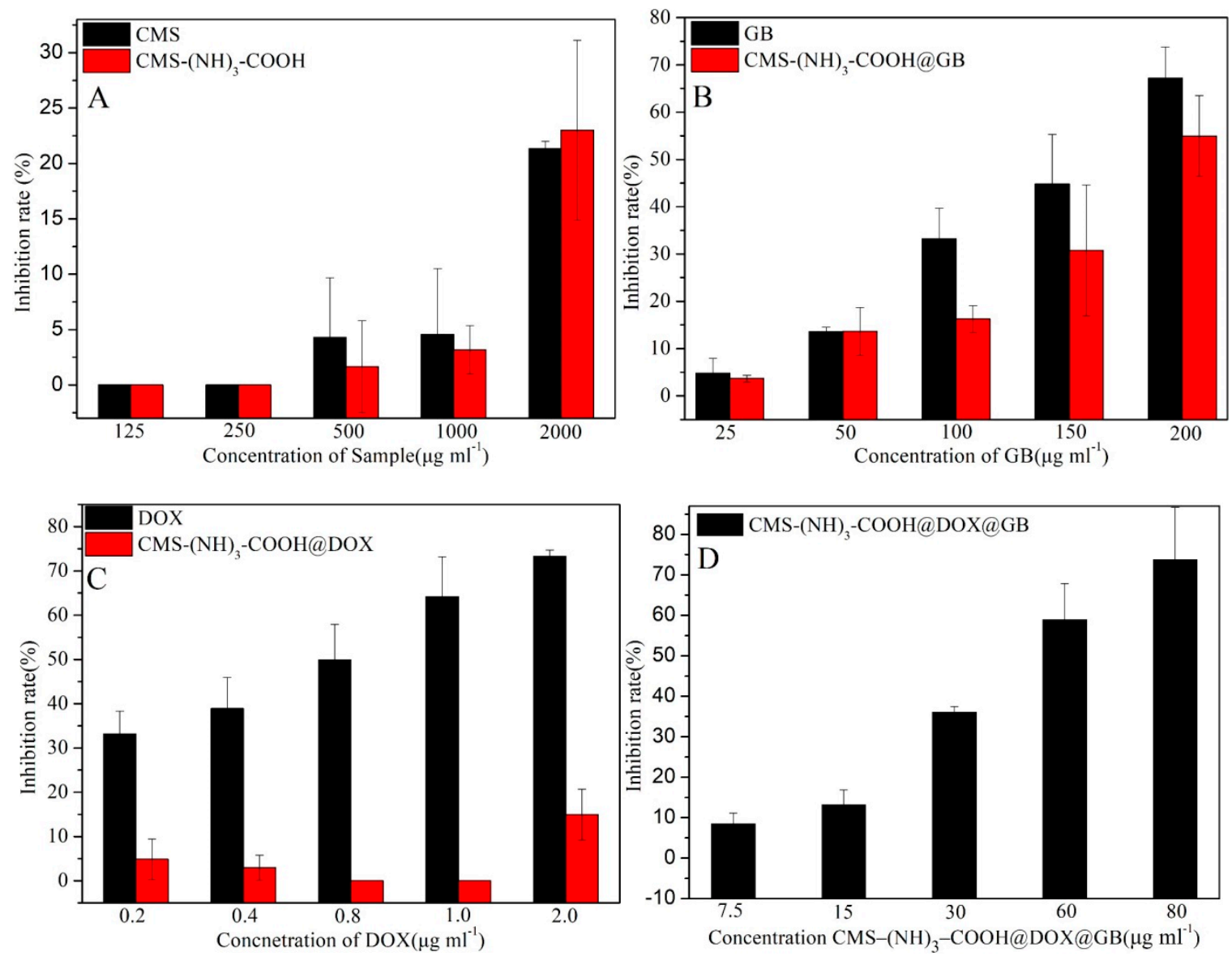

Figure 8. (A) is the in vitro inhibition rate of CMS and CMS- $(\mathrm{NH})_{3}-\mathrm{COOH}$; $(\mathbf{B})$ is the in vitro inhibition rate of GB and CMS- $(\mathrm{NH})_{3}-\mathrm{COOH} @ \mathrm{~GB} ;(\mathrm{C})$ is the in vitro inhibition rate of DOX and CMS- $(\mathrm{NH})_{3}-\mathrm{COOH} @ \mathrm{DOX}$ and $(\mathbf{D})$ is the in vitro inhibition rate of CMS-(NH) $)_{3}-\mathrm{COOH} @ \mathrm{DOX} @ \mathrm{~GB}$ for the treated A549 cells.

Viability studies also demonstrated that CMS- $(\mathrm{NH})_{3}-\mathrm{COOH} @ \mathrm{~GB}$ greatly increases the cell inhibition rate at concentrations as high as $644.08 \mu \mathrm{g} \cdot \mathrm{mL}^{-1}$, which is comparable to the cytotoxic effect of free GB (IC50, $\left.154.52 \mu \mathrm{g} \cdot \mathrm{mL}^{-1}\right)$. The independent CMS-(NH) $)_{3}-\mathrm{COOH} @$ GB and CMS-(NH) $)_{3}-\mathrm{COOH} @$ DOX had a lower efficacy for GB and DOX than the free GB and DOX (see Table 4). The half-maximum inhibitory concentration (IC50) value of CMS-(NH) $)_{3}-\mathrm{COOH} @$ DOX@GB against A549 cells was calculated to be approx. $51.27 \mu \mathrm{g} \cdot \mathrm{mL}^{-1}$, suggesting a fairly high therapeutic effectiveness and better synergies for DOX and GB. However, we expect that the CMS-(NH) $3-\mathrm{COOH} @ D O X @ G B$ selectively delivers the cytotoxic agent to acidic cancerous cells. 
Table 4. The half-maximum inhibitory concentration (IC50) values of samples for treating A549 cells.

\begin{tabular}{cc}
\hline Sample & Value of $\mathbf{I C}_{\mathbf{5 0}}\left(\boldsymbol{\mu g} \cdot \mathbf{m L}^{-\mathbf{1}}\right)$ \\
\hline CMS & - \\
CMS-(NH) $)_{3}-\mathrm{COOH}$ & - \\
CMS- $(\mathrm{NH})_{3}-\mathrm{COOH} @ G B$ & 644.08 \\
CMS- $(\mathrm{NH})_{3}-\mathrm{COOH} @$ DOX & - \\
CMS-(NH) $)_{3}-\mathrm{COOH} @$ DOX@GB & 51.27 \\
DOX & 0.8 \\
GB & 154.52 \\
\hline
\end{tabular}

\section{Release of DOX and GB}

Figure 9A-F shows the accumulative release curve of DOX and GB from CMS- $(\mathrm{NH})_{3}-$ COOH@DOX@GB, CMS-(NH) $3-\mathrm{COOH} @ D O X$, and CMS-(NH) $3-\mathrm{COOH} @ G B$ in different release fluids with different $\mathrm{pH}$ values ( $\mathrm{pH} 5.0$ and 7.4). At $\mathrm{pH} 7.4$, as shown in Figure $9 \mathrm{~A}$, the accumulative release rates of DOX and GB were $8.45 \%$ and $4.83 \%$, respectively, indicating that mesoporous materials increased GB solubility. We could obtain a result in which the GB first started to release and reached $0.25 \%$, but the DOX release rate was zero, and the release rate of GB exceeded that of DOX within 3 h (see Figure 9A,a). After $3 \mathrm{~h}$, the release of DOX gradually increased and surpassed GB. After $40 \mathrm{~h}$, the release curves of DOX and GB tended to be gentle (see Figure 9A). At pH 5.0, the accumulative release rates of DOX and GB were $32.03 \%$ and $13.66 \%$, respectively. The hydrogen bond reaction between the $-\mathrm{COOH}$ of the modified materials and the $-\mathrm{OH}$ and amine of drug molecule increased GB solubility and reached the acid solution better, as shown in Figure 9D. It is worth noting that DOX and GB were released simultaneously, with approximate release rates of $0.084 \%$ and $0.08 \%$, respectively. The release of DOX was continuously higher than that of GB (see Figure 9B,b). At pH 5.0 and 7.4, the general releasing trend of DOX was higher than GB, which related to the hydrophilia of DOX and the hydrophobia of GB. Figure 9E,F are the release curves of CMS- $(\mathrm{NH})_{3}-\mathrm{COOH} @ \mathrm{~GB}$ and CMS- $(\mathrm{NH})_{3}-\mathrm{COOH} @ \mathrm{DOX}$, respectively. The results show that, in the GB systems, the release rate of GB is higher than the system containing DOX and GB at pH 5.0. However, in the DOX systems, the release rate of DOX is lower than the system containing DOX and GB at $\mathrm{pH} 5.0$ and at $\mathrm{pH}$ 7.4, indicating that the release rate of DOX is enhanced in the system containing both drugs; however, the GB is weakened. The higher release rate of DOX and GB in the acid solution manifested the $\mathrm{pH}$ response property of CMS- $(\mathrm{NH})_{3}-\mathrm{COOH}$ (see Figure $\left.9 \mathrm{C}, \mathrm{D}\right)$. This shows that the carboxyl of the polyamine chain is more conducive to controlled drug release. 

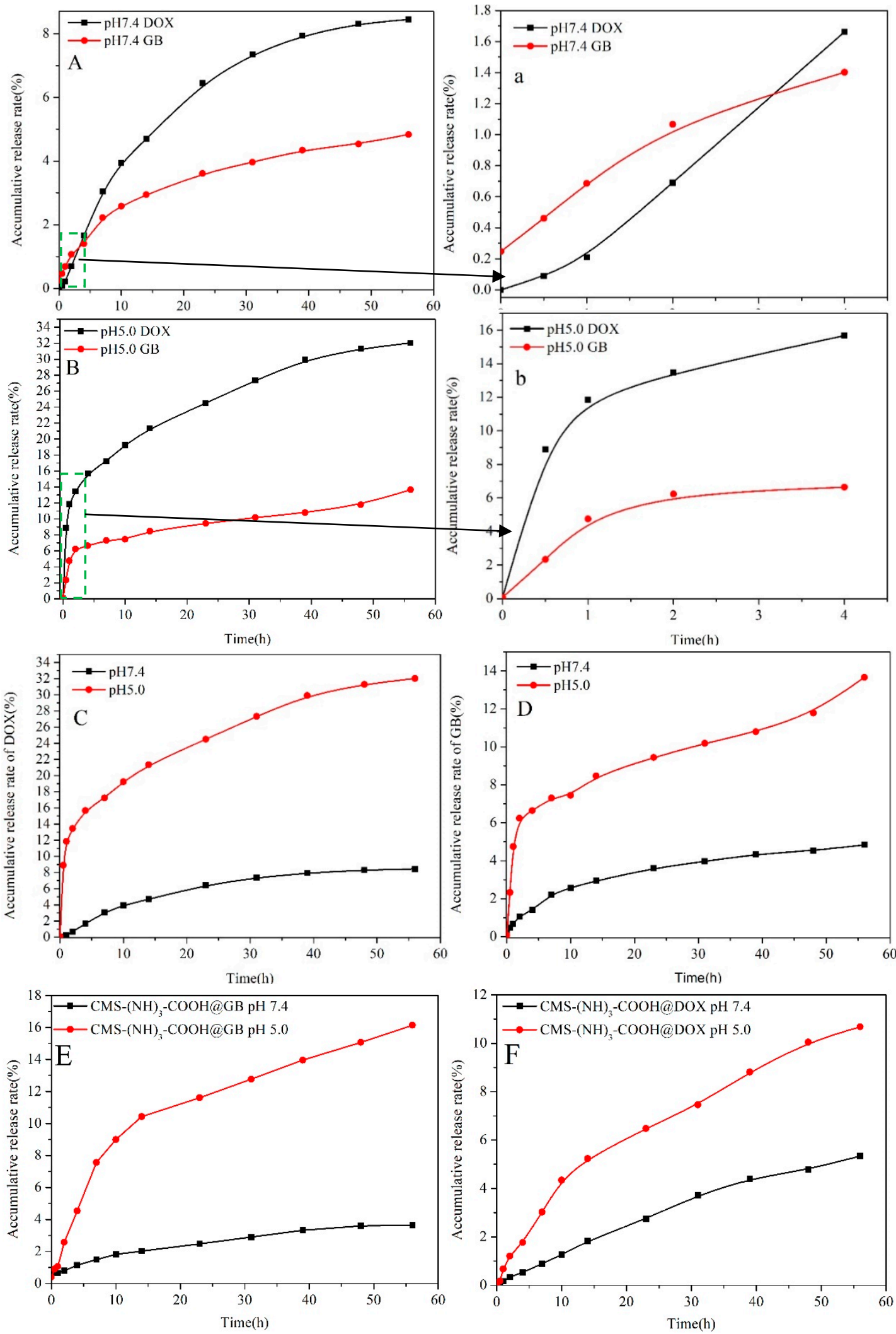

Figure 9. (A-D) are the accumulative release curves of DOX and GB from CMS- $(\mathrm{NH})_{3}-$ COOH@DOX@GB; (E): the accumulative release curves of GB from CMS-(NH) $)_{3}-\mathrm{COOH} @ G B$, and (F): the accumulative release curves of GB from CMS- $(\mathrm{NH})_{3}-\mathrm{COOH} @ \mathrm{DOX}$. The (a) shows the accumulative release curves of DOX and GB from (A) $4 \mathrm{~h}$ ago; The (b) shows the accumulative release curves of DOX and GB from (B) $4 \mathrm{~h}$ ago. 
A pH-controlled "open-close" mechanism (see Scheme 2) for the release of DOX and GB from CMS-(NH) $3-\mathrm{COOH} @$ DOX@GB could explain the phenomenon. With previous studies of different "open-close" mechanisms [42] at low $\mathrm{pH}(\mathrm{pH}$ 5.0), the hydrogen-bonding interactions between the electronegative CMS- $(\mathrm{NH})_{3}-\mathrm{COOH}$ and abundant positive charges in a weak acid solution could lead to the Coulomb attraction of head-head of CMS- $(\mathrm{NH})_{3}-\mathrm{COOH}$ greatly weakening or disappearing. However, multiamine chains could be protonated and could contribute to the generation of Coulombic repulsion; thus, the "open gate" of CMS- $(\mathrm{NH})_{3}-\mathrm{COOH}$ emerges. At a high $\mathrm{pH}(\mathrm{pH}$ 7.4), the Coulomb repulsion of head-head of CMS- $(\mathrm{NH})_{3}-\mathrm{COOH}$ would exist between the electronegative CMS- $(\mathrm{NH})_{3}-\mathrm{COOH}$ and abundant negative charges in a weak basic solution. However, the Coulombic attraction between positively charged multiamine chains and $\mathrm{CMS}-(\mathrm{NH})_{3}-\mathrm{COOH}$ in a weak basic solution leads to the appearance of the "close gate" of CMS- $(\mathrm{NH})_{3}-\mathrm{COOH}$. Thus, the release of DOX and GB at a low $\mathrm{pH}(\mathrm{pH} 5.0)$ was faster than at a high $\mathrm{pH}$ ( $\mathrm{pH} 7.4$, see Figure 9C,D).
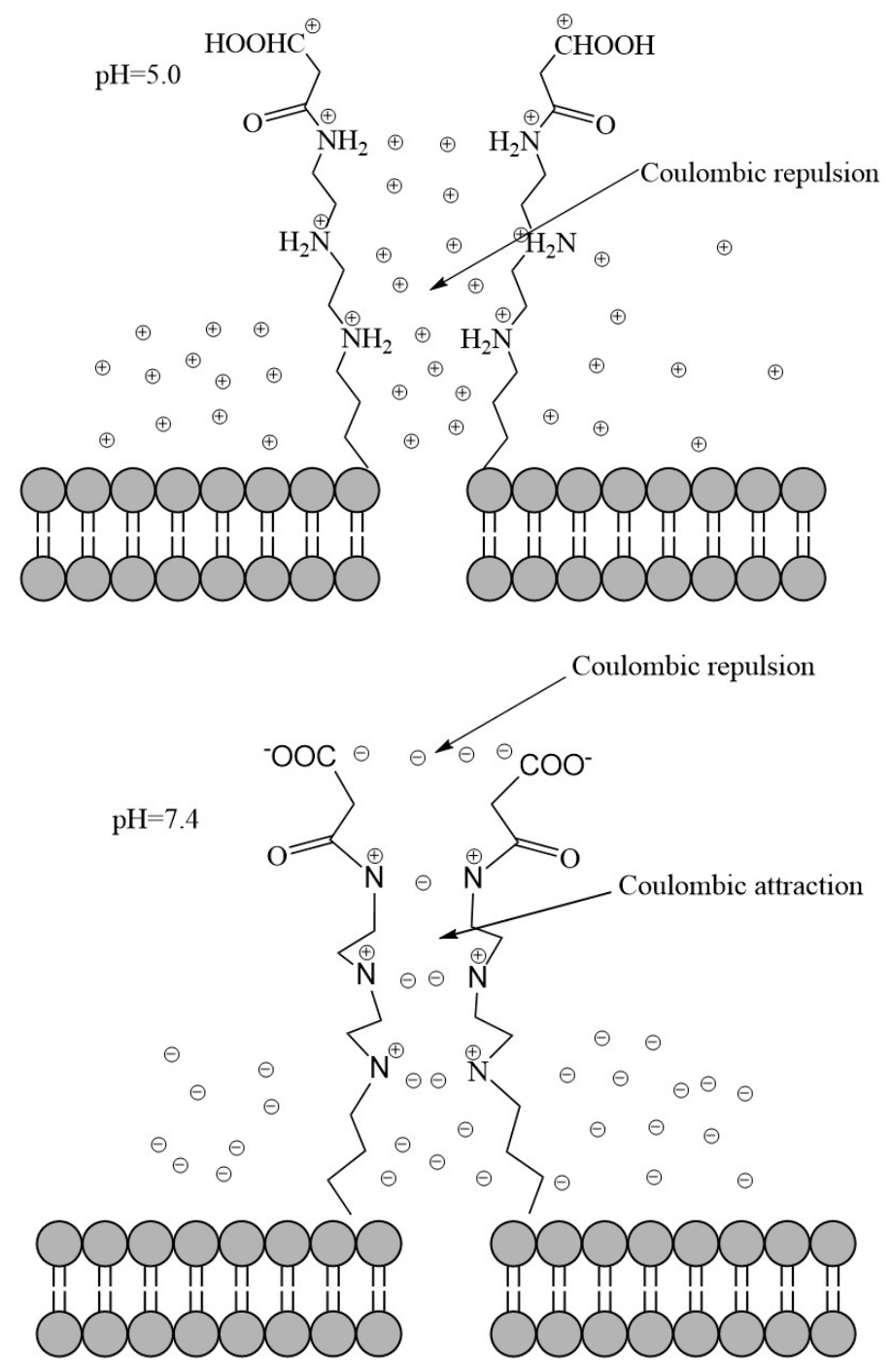

Scheme 2. The pH-controlled "open-close" mechanism for the release of DOX and GB from CMS-(NH) $3-\mathrm{COOH} @ D O X @ G B$.

\section{Conclusions}

In summary, we obtained a dual drug-delivery system through developing a $\mathrm{pH}$-sensitive carboxyl-functionalized large-pore CMS- $(\mathrm{NH})_{3}-\mathrm{COOH}$ to codeliver a synergistic gefitinib/DOX combination for A549 cells. Their release behavior could be separately controlled in response to 
different $\mathrm{pH}$ values. We used a $\mathrm{pH}$-controlled "open-close" mechanism (see Scheme 2), which better explained the release behaviors of DOX and GB from CMS- $(\mathrm{NH})_{3}-\mathrm{COOH} @ \mathrm{DOX} @ \mathrm{~GB}$. According to a cytotoxicity analysis, this double-drug system with microparticles and large pores makes GB and DOX have a good long-term synergistic therapeutic effect. This drug-delivery system is a valuable $\mathrm{pH}$ response strategy for the delivery of anticancer drugs, and it provides a potential strategy to overcome drug resistance.

Author Contributions: Conceptualization, Q.C.; data curation, F.S.; formal analysis, Y.L. and F.S.; funding acquisition, Y.L., J.Q., and Q.C.; investigation, F.S. and L.C.; methodology, Y.L. and F.S.; project administration, Y.L., J.Q., and Q.C.; resources, Y.L. and J.Q.; software, L.C.; supervision, Q.C.; validation, Q.C.; visualization, J.Q.; writing-original draft, F.S.; writing-review and editing, Y.L.

Funding: We acknowledge the financial support from the Guizhou provincial science and technology department joint fund project (QKHLH[2017]7289 and QKHPTRC[2017]5788) and the Sci-Tech Cooperation Foundation of Gui-zhou Province ([2012]7007).

Conflicts of Interest: There are no conflicts of interest to declare.

\section{References}

1. Fitzmaurice, C.; Akinyemiju, T.F.; Al Lami, F.H.; Alam, T.; Alizadeh-Navaei, R.; Allen, C.; Alsharif, U.; Alvis-Guzman, N.; Amini, E.; Anderson, B.O.; et al. Global, Regional, and National Cancer Incidence, Mortality, Years of Life Lost, Years Lived With Disability, and Disability-Adjusted Life-years for 29 Cancer Groups, 1990 to 2016: A Systematic Analysis for the Global Burden of Disease Study. JAMA Oncol. 2018, 4, 1553-1568. [PubMed]

2. Hashim, D.; Boffetta, P.; La Vecchia, C.; Rota, M.; Bertuccio, P.; Malvezzi, M.; Negri, E. The global decrease in cancer mortality: Trends and disparities. Ann. Oncol. 2016, 27, 926-933. [CrossRef] [PubMed]

3. Hasenstein, J.R.; Shin, H.C.; Kasmerchak, K.; Buehler, D.; Kwon, G.S.; Kozak, K.R. Anti-tumor activity of triolimus: A novel multi-drug loaded micelle containing paclitaxel, rapamycin and 17-aag. Mol. Cancer Ther. 2012, 11, 2233-2242. [CrossRef] [PubMed]

4. Cosco, D.; Paolino, D.; Cilurzo, F.; Casale, F.; Fresta, M. Gemcitabine and tamoxifen-loaded liposomes as multidrug carriers for the treatment of breast cancer diseases. Int. J. Pharm. 2012, 422, 229-237. [CrossRef] [PubMed]

5. Vasiliauskas, R.; Liu, D.; Cito, S.; Zhang, H.; Shahbazi, M.A.; Sikanen, T.; Mazutis, L.; Santos, H.A. Simple microfluidic approach to fabricate monodisperse hollow microparticles for multidrug delivery. ACS Appl. Mater. Interfaces 2015, 7, 14822-14932. [CrossRef] [PubMed]

6. Yu, C.; Qian, L.; Uttamchandani, M.; Li, L.; Yao, S.Q. Single-vehicular delivery of antagomir and small molecules to inhibit mir-122 function in hepatocellular carcinoma cells by using "smart" mesoporous silica nanoparticles. Angew. Chem. Int. Ed. 2015, 54, 10574-10578. [CrossRef] [PubMed]

7. Choi, J.Y.; Ramasamy, T.; Kim, S.Y.; Kim, J.; Ku, S.K.; Youn, Y.S.; Kim, J.R.; Jeong, J.H.; Choi, H.G.; Yong, C.S.; et al. Pegylated lipid bilayer-supported mesoporous silica nanoparticle composite for synergistic co-delivery of axitinib and celastrol in multi-targeted cancer therapy. Acta Biomater. 2016, 39, 94-105. [CrossRef] [PubMed]

8. Labala, S.; Jose, A.; Chawla, S.R.; Khan, M.S.; Bhatnagar, S.; Kulkarni, O.P.; Venuganti, V.V. Effective melanoma cancer suppression by iontophoretic co-delivery of stat 3 sirna and imatinib using gold nanoparticles. Int. J. Pharm. 2017, 525, 407-417. [CrossRef] [PubMed]

9. Kawano, K.; Hattori, Y.; Iwakura, H.; Akamizu, T.; Maitani, Y. Combination therapy with gefitinib and doxorubicin inhibits tumor growth in transgenic mice with adrenal neuroblastoma. Cancer Med. 2013, 2, 286-295. [CrossRef] [PubMed]

10. Li, J.; Xu, R.; Lu, X.; He, J.; Jin, S. A simple reduction-sensitive micelles co-delivery of paclitaxel and dasatinib to overcome tumor multidrug resistance. Int. J. Nanomed. 2017, 12, 8043-8056. [CrossRef] [PubMed]

11. Thorat, S.H.; Sahu, S.K.; Patwadkar, M.V.; Badiger, M.V.; Gonnade, R.G. Drug-drug molecular salt hydrate of an anticancer drug gefitinib and a loop diuretic drug furosemide: An alternative for multidrug treatment. J. Pharm. Sci. 2016, 104, 4207-4216. [CrossRef] [PubMed]

12. Roskoski, R., Jr. The erbb/her family of protein-tyrosine kinases and cancer. Pharmacol. Res. 2014, 79, 34-74. [CrossRef] [PubMed] 
13. Zhang, P.; Li, J.; Ghazwani, M.; Zhao, W.; Huang, Y.; Zhang, X.; Venkataramanan, R.; Li, S. Effective co-delivery of doxorubicin and dasatinib using a peg-fmoc nanocarrier for combination cancer chemotherapy. Biomaterials 2015, 67, 104-114. [CrossRef] [PubMed]

14. Hu, H.; Lin, Z.; He, B.; Dai, W.; Wang, X.; Wang, J.; Zhang, X.; Zhang, H.; Zhang, Q. A novel localized co-delivery system with lapatinib microparticles and paclitaxel nanoparticles in a peritumorally injectable in situ hydrogel. J. Control. Release 2015, 220, 189-200. [CrossRef] [PubMed]

15. He, Y.; Su, Z.; Xue, L.; Xu, H.; Zhang, C. Co-delivery of erlotinib and doxorubicin by ph-sensitive charge conversion nanocarrier for synergistic therapy. J. Control. Release 2016, 229, 80-92. [CrossRef] [PubMed]

16. Xu, X.; Li, L.; Zhou, Z.; Sun, W.; Huang, Y. Dual-ph responsive micelle platform for co-delivery of axitinib and doxorubicin. Int. J. Pharm. 2016, 507, 50-60. [CrossRef] [PubMed]

17. Sengupta, S.; Eavarone, D.; Capila, I.; Zhao, G.; Watson, N.; Kiziltepe, T.; Sasisekharan, R. Temporal targeting of tumour cells and neovasculature with a nanoscale delivery system. Nature 2005, 436, 568-572. [CrossRef] [PubMed]

18. Sun, J.; Liu, Y.; Chen, Y.; Zhao, W.; Zhai, Q.; Rathod, S.; Huang, Y.; Tang, S.; Kwon, Y.T.; Fernandez, C. Doxorubicin delivered by a redox-responsive dasatinib-containing polymeric prodrug carrier for combination therapy. J. Control. Release 2017, 258, 43-55. [CrossRef] [PubMed]

19. Zhou, Z.; Jafari, M.; Sriram, V.; Kim, J.; Lee, J.Y.; Ruiz-Torres, S.J.; Waltz, S.E. Delayed sequential co-delivery of gefitinib and doxorubicin for targeted combination chemotherapy. Mol. Pharm. 2017, 14, 4551-4559. [CrossRef] [PubMed]

20. Chen, Y.; Li, X.; Xiao, H.; Xiao, J.; Li, B.; Chen, X.; Wang, Y.; Cheng, D.; Shuai, X. Reduction and ph dual-sensitive nanovesicles co-delivering doxorubicin and gefitinib for effective tumor therapy. RSC Adv. 2018, 8, 2082-2091. [CrossRef]

21. Lu, J.; Liong, M.; Zink, J.I.; Tamanoi, F. Mesoporous silica nanoparticles as a delivery system for hydrophobic anticancer drugs. Small 2010, 3, 1341-1346. [CrossRef] [PubMed]

22. Zhu, Y.; Shi, J.; Shen, W.; Dong, X.; Feng, J.; Ruan, M.; Li, Y. Stimuli-responsive controlled drug release from a hollow mesoporous silica sphere/polyelectrolyte multilayer core-shell structure. Angew. Chem. Int. Ed. 2010, 117, 5213-5217. [CrossRef]

23. Kirkland, J.J.; Truszkowski, F.A.; Dilks, J.C.; Engel, G.S. Superficially porous silica microspheres for fast high-performance liquid chromatography of macromolecules. J. Chromatogr. A 2000, 890, 3-13. [CrossRef]

24. Yang, P.; Gai, S.; Lin, J. Functionalized mesoporous silica materials for controlled drug delivery. Chem. Soc. Rev. 2012, 43, 3679-3698. [CrossRef] [PubMed]

25. Lin, G.; Sun, J.; Li, Z.; Wang, J.; Ren, B. Influence of different structured channels of mesoporous silicate on the controlled ibuprofen delivery. Mater. Chem. Phys. 2012, 135, 786-797.

26. Xing, R.; Lin, H.; Jiang, P.; Qu, F. Biofunctional mesoporous silica nanoparticles for magnetically oriented target and ph-responsive controlled release of ibuprofen. Colloids Surf. A Physicochem. Eng. Asp. 2012, 403, 7-14. [CrossRef]

27. Gao, L.; Sun, J.; Zhang, L.; Li, Y.; Ren, B. Thermal decomposition behavior of amino groups modified bimodal mesoporous silicas as aspirin carrier. J. Nanosci. Nanotechnol. 2011, 11, 10324-10332. [CrossRef] [PubMed]

28. Wang, Y.; Sun, Y.; Wang, J.; Yang, Y.; Li, Y.; Yuan, Y.; Liu, C. Charge-reversal aptes-modified mesoporous silica nanoparticles with high drug loading and release controllability. ACS Appl. Mater. Interfaces 2016, 8, 17166-17175. [CrossRef] [PubMed]

29. Li, Y.; Song, F.; Guo, Y.; Cheng, L.; Chen, Q. Multifunctional Amine Mesoporous Silica Spheres Modified with Multiple Amine as Carriers for Drug Release. J. Nanomater. 2018, 2018, 1-10. [CrossRef]

30. Pang, J.; Li, X.; Zhou, G.; Sun, B.; Wei, Y. Fabrication of mesoporous silica nanospheres with radially oriented mesochannels by microemulsion templating for adsorption and controlled release of aspirin. RSC Adv. 2014, 5, 6599-6606. [CrossRef]

31. Gao, Q.; Xu, Y.; Wu, D.; Shen, W.; Deng, F. Synthesis, characterization, and in vitro ph-controllable drug release from mesoporous silica spheres with switchable gates. Langmuir 2010, 26, 17133-17138. [CrossRef] [PubMed]

32. Moreira, A.F.; Gaspar, V.M.; Costa, E.C.; de Melo-Diogo, D.; Machado, P.; Paquete, C.M.; Correia, I.J. Preparation of end-capped ph-sensitive mesoporous silica nanocarriers for on-demand drug delivery. Eur. J. Pharm. Biopharm. 2014, 88, 1012-1025. [CrossRef] [PubMed] 
33. Zhang, J.; Sun, Y.; Tian, B.; Li, K.; Wang, L.; Liang, Y.; Han, J. Multifunctional mesoporous silica nanoparticles modified with tumor-shedable hyaluronic acid as carriers for doxorubicin. Colloids Surf. B Biointerfaces 2016, 144, 293-302. [CrossRef] [PubMed]

34. Das, G.; Nicastri, A.; Coluccio, M.L.; Gentile, F.; Candeloro, P.; Cojoc, G.; Liberale, C.; De Angelis, F.; Di Fabrizio, E. Ft-ir, raman, rrs measurements and dft calculation for doxorubicin. Microsc. Res. Tech. 2010, 73, 991-995. [CrossRef] [PubMed]

35. Shen, G.F.; Liu, T.T.; Wang, Q.; Jiang, M.; Shi, J.H. Spectroscopic and molecular docking studies of binding interaction of gefitinib, lapatinib and sunitinib with bovine serum albumin (bsa). J. Photochem. Photobiol. B Biol. 2015, 153, 380-390. [CrossRef] [PubMed]

36. Barrett, E.P.; Joyner, L.G.; Halenda, P.P. The determination of pore volume and area distributions in porous substances. I. computations from nitrogen isotherms. J. Am. Chem. Soc. 1951, 73, 373-380. [CrossRef]

37. Kruk, M.; Jaroniec, M. Gas adsorption characterization of ordered organic-inorganic nanocomposite materials. Chem. Mater. 2001, 13, 3169-3183. [CrossRef]

38. Brunauer, S.; Emmett, P.H.; Teller, E. Adsorption of gases in multimolecular layers. J. Am. Chem. Soc. 1938, 60, 309-319. [CrossRef]

39. Silva, A.L.; Sousa, K.S.; Germano, A.F.; Oliveira, V.V.; Espínola, J.G.; Fonseca, M.G.; Airoldi, C.; Arakaki, T.; Arakaki, L.N. A new organofunctionalized silica containing thioglycolic acid incorporated for divalent cations removal-A thermodyamic cation/basic center interaction. Colloids Surf. A Physicochem. Eng. Asp. 2009, 332, 144-149. [CrossRef]

40. Zhao, Q.; Geng, H.; Wang, Y.; Gao, Y.; Huang, J.; Wang, Y.; Zhang, J.; Wang, S. Hyaluronic acid oligosaccharide modified redox-responsive mesoporous silica nanoparticles for targeted drug delivery. ACS Appl. Mater. Interfaces 2014, 6, 20290-20299. [CrossRef] [PubMed]

41. Cheng, W.; Liang, C.; Xu, L.; Liu, G.; Gao, N.; Tao, W.; Luo, L.; Zuo, Y.; Wang, X.; Zhang, X.; et al. Tpgs-functionalized polydopamine-modified mesoporous silica as drug nanocarriers for enhanced lung cancer chemotherapy against multidrug resistance. Small 2017, 13, 1700623. [CrossRef] [PubMed]

42. Casasús, R.; Marcos, M.D.; Martínez-Máñez, R.; Ros-Lis, J.V.; Soto, J.; Villaescusa, L.A.; Amorós, P.; Beltrán, D.; Guillem, C.; Latorre, J. Toward the development of ionically controlled nanoscopic molecular gates. J. Am. Chem. Soc. 2004, 126, 8612-8613. [CrossRef] [PubMed] 